\section{The Oncogenic Roles of TRPM Ion Channels in Cancer}

Running title: Roles of TRPM Ion Channels in Cancer

$$
\text { Kah Keng Wong }{ }^{1} \text {, Alison H. Banham², Nik Soriani Yaacob }{ }^{3} \text {, Siti Muhamad Nur Husna }{ }^{1}
$$

\section{Affiliations:}

${ }^{1}$ Department of Immunology, School of Medical Sciences, Universiti Sains Malaysia, 16150 Kubang Kerian, Kelantan, Malaysia

${ }^{2}$ Nuffield Division of Clinical Laboratory Sciences, Radcliffe Department of Medicine, University of Oxford, John Radcliffe Hospital, Oxford OX3 9DU, United Kingdom

${ }^{3}$ Department of Chemical Pathology, School of Medical Sciences, Universiti Sains Malaysia, Health Campus, 16150 Kubang Kerian, Kelantan, Malaysia

\section{Corresponding author:}

Dr. Kah Keng Wong (BSc, Mal; DPhil, Oxon)

Department of Immunology,

School of Medical Sciences,

Universiti Sains Malaysia,

16150 Kubang Kerian, Kelantan, Malaysia

Tel: +6097676229; Fax: +6097653370; E-mail: kahkeng@usm.my

5

16

27




\section{ABSTRACT}

Transient receptor potential (TRP) proteins are a diverse family of ion channels present in

37 multiple types of tissues. They function as gatekeepers for responses to sensory stimuli 38 including temperature, vision, taste and pain through their activities in conducting ion fluxes. The 39 TRPM (melastatin) subfamily consists of eight members (i.e. TRPM1-8) which collectively 40 regulate fluxes of various types of cations such as $\mathrm{K}^{+}, \mathrm{Na}^{+}, \mathrm{Ca}^{2+}$ and $\mathrm{Mg}^{2+}$. Growing evidence in 41 the past two decades indicates that TRPM ion channels, their isoforms or long non-coding 42 RNAs encoded within the locus may be oncogenes involved in the regulation of cancer cell 43 growth, proliferation, autophagy, invasion and epithelial-mesenchymal transition, and their 44 significant association with poor clinical outcomes of cancer patients. In this review, we describe 45 and discuss recent findings implicating TRPM channels in different malignancies, their 46 functions, mechanisms and signaling pathways involved in cancers, as well as summarizing 47 their normal physiological functions and the availability of ion channel pharmacological 48 inhibitors.

\section{KEYWORDS}

51 TRPM; Oncogenes; Isoforms; IncRNA 


\section{INTRODUCTION}

Ion channels are specialized membrane proteins that mediate ion fluxes. Their roles in shaping rapid signals in excitable cells such as neurons and cardiac myocytes have been widely known and traditionally studied by physiologists and biophysicists. Nonetheless, ion channels have been implicated in the development of various pathologies including cancer. Pioneering studies in the 1990s demonstrating the oncogenic properties of $\mathrm{K}^{+}$channels sparked interest in examining the potential to target ion channels in malignancies (Arcangeli et al., 1993; Pardo et al., 1999). These proteins have since been subject to intensive investigations, and ion channels were found to be involved in processes crucial for non-excitable and cancer cells including maintaining cell viability, proliferation, cell adhesion and migration (Leanza, Manago, Zoratti, Gulbins, \& Szabo, 2016). It has been proposed that ion channels are a novel hallmark of cancer termed as 'oncochannels' (Huber, 2013; Kale, Amin, \& Pandey, 2015), and growing evidence supports the recent proposal of classifying cancer with ion channel dysfunction as oncochannelopathy (Prevarskaya, Skryma, \& Shuba, 2018).

Transient receptor potential (TRP) ion channels were originally identified in Drosophila where mutation of trp and trpl genes caused transient depolarization and receptor potential (Hardie, \& Minke, 1992). In mammals, TRP channels are divided into six subfamilies based on shared sequence homology: TRPA (ankyrin), TRPC (canonical), TRPM (melastatin), TRPML (mucolipin), TRPP (polycystin) and TRPV (vanilloid) (Leanza et al., 2016). Physiologically, TRP channels act as gatekeepers for responses to sensory stimuli including temperature, vision, taste and pain via their functional ability to conduct ion fluxes.

There are eight members within the TRPM subfamily (TRPM1-8) and each consists of six transmembrane domains with a pore-forming loop, and the $\mathrm{N}$ - and C-termini directed towards the cytoplasm (Schmitz, \& Perraud, 2005; Sumoza-Toledo, \& Penner, 2011). By mediating fluxes of cations (e.g. $\mathrm{K}^{+}, \mathrm{Na}^{+}, \mathrm{Ca}^{2+}, \mathrm{Mg}^{2+}$ and $\mathrm{Zn}^{2+}$ ), TRPM channels regulate diverse types of physiological processes such as night vision (TRPM1), immune responses (TRPM2), heat sensitivity (TRPM2 and TRPM3), artery vasoconstriction (TRPM4), taste-signaling and insulin secretion (TRPM5), magnesium absorption (TRPM6 and TRPM7), and cold sensation (TRPM8) (Figure 1). 


\section{TRPM PROTEINS IN MALIGNANCIES}

Accumulating evidence has demonstrated the oncogenic roles of several TRPM proteins as shown through gene knockdown, knockout or overexpression methodologies both in human cancer cell lines and experimental animal models, while others may function as tumor suppressors. In this review, we discuss and summarize the association of each TRPM ion channel with various cancers, and their potential as therapeutic targets in human malignancies. The normal physiological functions of each TRPM are first introduced before their relevance with cancers are described and discussed. In addition, the list of pharmacological inhibitors against each TRPM protein member is listed in Table 1. The inhibitors were selected based on evidence showing TRPM currents or ion flux activities were reduced by the treatment with each antagonist, and $\mathrm{IC}_{50}$ value of $\leq 10 \mu \mathrm{M}$ (except TRPM1, TRPM5 and TRPM6). The $10 \mu \mathrm{M}$ cut-off was employed to shortlist the inhibitors as it was considered to represent both marginally and highly active inhibitors (Koutsoukas et al., 2013; Mervin et al., 2015).

\subsection{TRPM1: Reduced Expression in Melanoma Progression}

The founding member of the TRPM family, TRPM1, was initially identified as a gene whose transcript expression was downregulated in a metastatic mouse melanoma cell line (Duncan et al., 1998). The ion channel is also known as melastatin due to its expression in melaninproducing melanocytes (Duncan et al., 1998; Zhiqi et al., 2004).

TRPM1 is a non-selective cation channel (permeable to $\mathrm{Na}^{+}, \mathrm{Ca}^{2+}$ ) that is thought to be constitutively open and its closure is activated by heterotrimeric G-proteins (Xu et al., 2016). Physiologically, TRPM1 plays crucial roles in triggering the depolarization of ON-bipolar cells of the retina through the metabotropic glutamate receptor 6 (mGluR6) cascade, enabling synaptic transmission of light in the eye and maintaining normal vision (Koike et al., 2010). Indeed, TRPM1 mutations are a common cause of autosomal-recessive congenital stationary night blindness (CSNB) (van Genderen et al., 2009; Zhou et al., 2016). Mutations affecting exons 4, 5, 16 and 20 of TRPM1 were reported in preschool-aged children with complete CSNB (cCSNB), and that TRPM1-associated CCSNB should be suspected in preschool-aged children with high levels of myopia (Miraldi Utz et al., 2018). Additionally, intronic TRPM1 nuclear single nucleotide polymorphisms (nSNPs) are highly associated with age-related macular degeneration (Persad et al., 2017). 
131 In malignancies, studies have focused on the association of reduced TRPM1 expression in

132 melanoma progression. TRPM1 transcripts were commonly expressed in benign melanocytic

133 proliferations but lost in $51 \%$ of primary cutaneous melanomas, $53 \%$ of invasive melanomas

134 and $100 \%$ of melanoma metastases, indicating a gradual loss of TRPM1 expression during

135 progression to invasive and metastatic disease (Deeds, Cronin, \& Duncan, 2000). Subsequent

136 studies utilizing in situ hybridization demonstrated that higher TRPM1 mRNA expression was

137 significantly associated with prolonged disease-free survival (DFS) $(p<0.0001)$, and that TRPM1

138 status together with tumor thickness could identify patients with a high risk of metastatic disease

139 (Duncan et al., 2001).

140

141 These findings were also reproduced in a recent study demonstrating loss of TRPM1 in the

142 progression of melanoma to a metastatic phenotype that was significantly associated with worse

143 DFS $(p<0.0001)$ and overall survival (OS) $(p<0.0001)$ (Brozyna et al., 2017). Moreover, TRPM1

144 autoantibodies targeting exons 9 and 10 of human TRPM1 gene were present in melanoma145 associated retinopathy, a paraneoplastic syndrome associated with melanomas (Duvoisin et al., 146 2017). Interestingly, intron 6 of TRPM1 encodes the microRNA miR-211, which has been shown 147 to disrupt melanoma metastasis through transcriptional suppression of multiple oncogenes 148 (Levy et al., 2010), suggesting a miR-regulated tumor suppressive mechanism linked to the 149 TRPM1 locus.

A thorough literature search did not yield further information or studies pertaining to TRPM1

152 expression in other malignancies. The suspected role of TRPM1 in melanoma suppression is 153 only based on correlation studies, and direct functional evidence on how TRPM1 affects cancer 154 biology is lacking. Moreover, it remains unknown if TRPM1 plays oncogenic roles in other malignancies and this represents an interesting avenue for further investigations.

\subsection{TRPM2: Oncogenic Nuclear Localization and the Long ncRNA (IncRNA) TRPM2-AS}

158 TRPM2 (permeable to $\mathrm{Ca}^{2+}, \mathrm{Na}^{+}, \mathrm{K}^{+}$) is gated by adenosine diphosphate (ADP) ribose, and it is 159 potently activated by reactive oxygen species (ROS) (Kolisek, Beck, Fleig, \& Penner, 2005). In neurons, TRPM2 is required to generate heat sensitivity (Tan, \& McNaughton, 2016), and the ion channel also limits fever and drives hypothermia (Song et al., 2016). TRPM2 is also

162 expressed in various immune cells including monocytes, macrophages, neutrophils, dendritic 
cells and lymphocytes, playing crucial roles in both innate and adaptive immunity but its excessive activity in immune cells contributes to inflammatory and autoimmune diseases (Syed Mortadza, Wang, Li, \& Jiang, 2015). For instance, TRPM2 was required by the type II transmembrane protein CD38 to induce chronic inflammation and increase susceptibility to experimental lupus shown in $\mathrm{Cd}_{3} 8^{-/}$and $\mathrm{Trpm}^{-/-}$murine models (Garcia-Rodriguez et al., 2018). TRPM2 also plays other crucial physiological roles including regulating neuronal growth and survival. The ion channel's expression was increased by neurotoxins (1-methyl-4phenylpyridinium) through ROS production that subsequently promoted death of neuronal cells (Sun et al., 2018b), and $\mathrm{Ca}^{2+}$ influx via TRPM2 promoted ROS production leading to death of rat cortical neuronal cells (Kaneko et al., 2006), suggesting a role of TRPM2 in neuronal degeneration and Parkinson's disease.

There have been numerous studies investigating TRPM2 in both hematological and solid tumors. TRPM2 depletion retarded growth of neuroblastoma cells with increased sensitivity to doxorubicin both in vitro (SH-SY5Y cells) and in vivo in xenografts (TRPM2-depleted SH-SY5Y cells in nude-FOXn1 ${ }^{\text {nu }}$ mice) (Bao et al., 2016). The mechanism was reported to be through TRPM2-mediated $\mathrm{Ca}^{2+}$ entry that increased mitochondrial ROS and cellular bioenergetics. In gastric cancer cells (AGS and MKN-45), TRPM2 knockdown downregulated the c-Jun Nterminal kinase (JNK) signaling pathway that subsequently impaired autophagy and mitophagy, leading to mitochondria defects and cell death (Almasi et al., 2018). The authors also found that TRPM2 downregulation sensitized gastric cancer cells to paclitaxel and doxorubicin. In pancreatic ductal adenocarcinoma (PDAC), mutated $(p=0.010)$ or increased $(p=0.042)$ TRPM2 expression was significantly associated with inferior patient survival, and TRPM2 overexpression in PDAC cells (PANC-1) induced cell proliferation, invasion and metastatic capabilities (Lin et al., 2018). Inhibition of TRPM2 also induced cell cycle arrest resulting in the death of T-cell leukemia cells (Jurkat) (Klumpp et al., 2016). Recently, the cryo-electron microscopy (cryo-EM) structure of human, zebrafish or sea anemone TRPM2 and its gating mechanism have been uncovered where the channel opening is activated by both ADP-ribose (ADPR) and $\mathrm{Ca}^{2+}$ binding (Huang, Winkler, Sun, Lu, \& Du, 2018; Wang et al., 2018a; Zhang, Toth, Szollosi, Chen, \& Csanady, 2018). 
194 Furthermore, the IncRNA TRPM2-AS, an antisense transcript of TRPM2 consisting of three 195 exons at $875 \mathrm{nt}$ in length, was overexpressed in prostate cancer and significantly associated 196 with worse survival $\left(p=1.57 \times 10^{-7}\right)$ and relapse $\left(p=1.24 \times 10^{-3}\right)$. Its knockdown led to the death 197 of prostate cancer cells (PC3; TRPM2-AS siRNA in vitro and in immunodeficient mice) through excessive increase in cellular stress, intracellular hydrogen peroxide and cell cycle arrest 199 (Orfanelli et al., 2015). TRPM2-AS was also highly expressed in non-small cell lung cancer 200 (NSCLC) tissues with elevated TRPM2-AS expression linked with significantly inferior survival 201 ( $p=0.003)$, Furthermore, TRPM2-AS knockdown promoted apoptosis of NSCLC cells (A549 and 202 H129), partially through inhibition of SHC1 expression (Huang et al., 2017a). TRPM2-AS was more highly expressed in cisplatin-resistant NSCLC A549/DDP cells, and re-sensitization to cisplatin was observed in these cells after TRPM2-AS knockdown through activation of the p53p66 ${ }^{\text {shc }}$ pathway (Ma et al., 2017).

However, context-dependent tumor suppressive roles of TRPM2 have also been documented. Treatment of bladder cancer cells (T24) with histone deacetylase inhibitor (HDACi) induced cell apoptosis through upregulation of TRPM2 expression, and TRPM2 depletion antagonized HDACi-induced apoptosis (Cao et al., 2015). The anti-tumor activity of natural killer (NK) cells requires TRPM2-mediated $\mathrm{Ca}^{2+}$ signaling that promotes degranulation and cytotoxicity of NK cells against B16F10 melanoma cells as demonstrated by NK cells from Trpm2 ${ }^{-/}$mice (Rah, Kwak, Chung, \& Kim, 2015), thus targeting TRPM2 might reduce normal anti-tumor activities. In addition, activation of TRPM2-CaMKII ( $\mathrm{Ca}^{2+} /$ calmodulin-dependent protein kinase II, a serine/threonine-specific protein kinase crucial for several physiological processes) by ROS induced death of HeLa (cervical cancer) or PC-3 (prostate cancer) cell lines (Wang, Huang, \&

217 Yue, 2017). Recently, it has been shown that although breast cancer cells (MDA-MB-231) with

218 reduced levels of TRPM2 demonstrated growth retardation, these cells were protected from 219 anti-tumor neutrophil cytotoxicity and showed a more aggressive phenotype through increased 220 metastatic seeding (Gershkovitz et al., 2018).

222 As both oncogenic and potentially tumor suppressive roles of TRPM2 have been demonstrated, 223 depending on cancer types, care will need be taken when considering TRPM2 as a bona fide 224 target for cancer therapy. Moreover, as numerous normal cell populations express TRPM2 and 
the ion channel regulates a wide variety of important processes, targeting TRPM2 might result in organ toxicities or disruption of normal physiological processes.

We suggest the following future investigations to elucidate its potential as a cancer therapeutic target:

(i) TRPM2 was found to be located in the nuclei of prostate cancer cells (PC-3 and DU-145) but not in benign prostate cells (BPH-1) where it showed membranous or cytoplasmic localization (Zeng et al., 2010). In these cells, abundant TRPM2 was translocated into the nucleus that subsequently inhibited nuclear ADP-ribosylation, and the authors proposed that TRPM2 might have enzymatic function in the nucleus. In line with this observation, TRPM2 deletion inhibited migratory abilities and induced apoptosis of oral squamous carcinoma cells (SCC-9) where a significant amount of the protein was present in nuclei of SCC9 cells in contrast with its absence in the nuclei of non-malignant human tongue samples (Zhao et al., 2016). Hence, the oncogenic roles of TRPM2 might be attributable to its activities dependent on its altered subcellular localization, and this warrants further investigation.

(ii) Instead of targeting TRPM2 per se, TRPM2-AS represents an alternative therapeutic avenue as the IncRNA is expressed at low levels in healthy tissues but it is upregulated in various human cancer cells (melanoma, breast and lung cancers) (Orfanelli et al., 2008), as well as prostate cancer and NSCLC (Huang et al., 2017a; Ma et al., 2017). Thus, investigations into TRPM2-AS-specific inhibitory agents may be desirable in the context of TRPM2-AS-associated cancer therapy.

\subsection{TRPM3: Promotes Growth and Autophagy in Clear Cell Renal Cell Carcinoma (ccRCC)} TRPM3 (permeable to $\mathrm{Ca}^{2+}, \mathrm{Zn}^{2+}, \mathrm{Mn}^{2+}$ ) was the most recently identified ion channel of the TRPM family, and is activated by steroid or heat depending on the cell type. In pancreatic beta cells, TRPM3 is activated by the steroid pregnenolone sulfate that leads to $\mathrm{Ca}^{2+}$ influx and increased insulin secretion (Wagner et al., 2008). Through induction by pregnenolone sulfate, TRPM3 regulates proliferation and contractility of vascular smooth muscle cells (Naylor et al., 2010), and TRPM3 mRNA has been shown to be upregulated by a set of nine circular RNAs (circRNAs) in coronary artery disease patients (Pan et al., 2017). 
In somatosensory neurons, TRPM3 functions as a nociceptor channel to detect noxious heat (Vriens et al., 2011) and to evoke pain through neuropeptide release from nerve terminals in the skin (Held et al., 2015). Owing to its involvement in triggering the activities of pain-sensing nerve cells, antagonizing TRPM3 has been proposed to be a potential analgesic strategy (Dembla et al., 2017). In osteoblast cells, downregulation of TRPM3 expression by puerarin (an isoflavonoid phytoestrogen) or siRNAs promoted their proliferation and differentiation, suggesting TRPM3 as a potential therapeutic target in osteoporosis (Zeng et al., 2018).

TRPM3 knockdown or treatment with TRPM3 inhibitor mefenamic acid in human ccRCC cell lines (786-O and A498) with inactive von Hippel-Lindau (VHL) tumor suppressor disrupted formation and growth of tumors in xenografts (athymic nude mice). These observations were reversed through reconstitution of TRPM3 expression (Hall et al., 2014). The authors demonstrated that such tumor growth was achieved through increased autophagy by TRPM3 promoting $\mathrm{Ca}^{2+}$ influx, leading to activation of several downstream proteins (CAMKK2, AMPK, ULK1, LC3A and LC3B) important for phagophore formation and autophagy. Furthermore, the authors demonstrated that TRPM3 was directly suppressed by VHL through miR-204, identifying the signaling cascade that regulated TRPM3 activities as well as its downstream signaling pathway.

MiR-204 is expressed from intron 6 of the human TRPM3 gene, suggesting that they both share common regulatory mechanisms. MiR-204 has been frequently documented to play tumor suppressive roles in various malignancies including gastric cancer (Sacconi et al., 2012), head and neck (Lee et al., 2010) and other tumor types (Li, Pan, \& Li, 2016). MiR-204 inhibited the translation of its host gene TRPM3 in ccRCC by binding to miR-204 site in the 3'UTR (Hall et al., 2014), establishing a TRPM3-miR-204 regulatory circuit whose disruption may lead to cellular transformation into ccRCC. Gene expression profiling demonstrated that TRPM3 was one of 23 genes upregulated by over seven-fold in human choroid plexus papilloma cells versus normal choroid plexus epithelial cells, and the observations were validated by quantitative RTPCR (Hasselblatt et al., 2009), although the functional significance of TRPM3 in the disease remains unexplored. 
TRPM3 and the tumor suppressor miR-204 might share common expression regulators as miR204 downregulation in gliomas was due to hypermethylation of TRPM3 promoter (Ying et al., 2013), and the expression of miR-204 was significantly associated with TRPM3 expression (Courboulin et al., 2011). Interestingly, miR-204 expression was positively-associated with two shorter isoforms of TRPM3 but not with the full-length protein in ccRCC (Mikhaylova et al., 2012). Investigations on TRPM3 isoforms, its full-length protein as well as the levels of miR-204 in malignancies are recommended as these molecules might play distinct and potentially opposing roles in tumorigenesis. It would also be of interest to evaluate the significance of the TRPM3-miR-204 circuit in different types of cancer.

Nonetheless, there also appears to be data suggesting tumor suppressive roles for TRPM3. In a bioinformatics-driven approach of re-analyzing gene expression profiling datasets, increased TRPM3 transcript expression was associated with decreased risk for bladder, breast and thyroid cancers, and its mRNA was broadly downregulated in various cancer types (Park et al., 2016). It is plausible that TRMP3 inhibition as a therapeutic strategy may be restricted to certain cancer types where it functions as an oncochannel.

\subsection{TRPM4: A Potential Oncochannel in Prostate Cancer and Diffuse Large B-cell} Lymphoma (DLBCL)

TRPM4, along with its closest homologue TRPM5, differs from other members of the TRPM family as it allows the influx of only monovalent cations $\left(\mathrm{Na}^{+}, \mathrm{K}^{+}\right)$and it is impermeable to $\mathrm{Ca}^{2+}$. TRPM4 is activated by increased concentration of cytoplasmic $\mathrm{Ca}^{2+}\left[\mathrm{Ca}^{2+}\right]_{1}$ (Launay et al., 2004; Launay et al., 2002). TRPM4 is expressed in numerous tissues including the central nervous system where it contributes to myogenic vasoconstriction of cerebral arteries (Earley, Waldron, \& Brayden, 2004), and in various immune cells (e.g. dendritic, mast and Th1 cells) where it mainly promotes their migration (Barbet et al., 2008; Weber, Hildner, Murphy, \& Allen, 2010).

TRPM4 has been implicated in numerous cardiovascular disorders. Knockdown of TRPM4 via siRNA enhanced angiogenesis after ischemic stroke (Loh et al., 2014). TRPM4 regulates the development of cardiac hypertrophy (Kecskes et al., 2015) and is capable of limiting hypertension (Mathar et al., 2010). In addition, mutations of TRPM4 have been found in long QT syndrome (Hof et al., 2017) and progressive familial heart block type I (Daumy et al., 2016) 
where the latter disease having a gain-of-function TRPM4 mutation. One of the pathogenic mechanisms contributing to cardiac disorders is the presence of mutant TRPM4 proteins with altered TRPM4 half-life compared to the wild-type TRPM4 protein (Bianchi, Ozhathil, MedeirosDomingo, Gollob, \& Abriel, 2018). In rat models with stroke, TRPM4 inhibition demonstrated tissue salvage and improved blood-brain barrier integrity after ischemic stroke reperfusion, suggesting the use of TRPM4 inhibitors for early stroke reperfusion (Chen et al., 2018).

TRPM4 consists of at least two isoforms, TRPM4a and TRPM4b the latter being the long form that has been referred to as TRPM4 since 2004 (Launay et al., 2004). Both TRPM4 and TRPM5 are activated by the rise of intracellular $\mathrm{Ca}^{2+}$ and can be activated by heat (Talavera et al., 2005). However, both channels share some distinct features in which TRPM4 is expressed in wide variety of human tissues while TRPM5 expression is mostly restricted in taste receptors; the temperature sensitivity of TRPM5 underlies the enhanced sweetness perception at high temperatures when this receptor is activated (Talavera et al., 2005). Nonetheless, it has recently been shown that TRPM5 is not solely responsible for TRP-mediated taste signaling and that both TRPM4 and TRPM5 are required for taste transduction to detect bitter, sweet or umami stimuli (Dutta Banik, Martin, Freichel, Torregrossa, \& Medler, 2018).

In terms of its role in malignancy, growing evidence has shown TRPM4's association with prostate cancer. TRPM4 was identified as one of five candidate driver genes involved in androgen-independent prostate cancer (AIPC; characterized by the resistance to the standard androgen-deprivation therapy) (Schinke et al., 2014). TRPM4 levels were overexpressed in prostate cancer tissues compared to non-malignant or benign prostate tissues at both the mRNA (Schinke et al., 2014) and protein levels (Berg et al., 2016; Holzmann et al., 2015). TRPM4 was weakly expressed in non-malignant or benign prostatic hyperplasia cells, but moderately or strongly expressed in prostatic intraepithelial neoplasia and prostate cancer (Holzmann et al., 2015). Increased TRPM4 protein expression was also significantly associated with higher risk of biochemical recurrence in prostate cancer patients $(p=0.043)$ (Berg et al., 2016).

Functionally, in prostate cancer cell lines (DU145 and PC3), TRPM4 knockdown by siRNA conferred decreased migration without effects on proliferation (Holzmann et al., 2015). In 
DU145 cells, this might be due to TRPM4 allowing large $\mathrm{Na}^{+}$influx, leading to depolarization of the membrane potential that subsequently decreased the driving force for $\mathrm{Ca}^{2+}$ entry and reduced store-operated $\mathrm{Ca}^{2+}$ entry (SOCE) (Holzmann et al., 2015). In a recent independent study (Sagredo et al., 2018), TRPM4 silencing by shRNA decreased proliferation of PC3 cells (migration was not investigated) with lower levels of phosphorylated AKT1 and increased $\beta$ catenin GSK-3 $\beta$-dependent phosphorylation that could promote $\beta$-catenin degradation. The expression of $\beta$-catenin target genes was also significantly decreased and activities of GSK-3 $\beta$ were increased in TRPM4-depleted PC3 cells, suggesting the involvement of TRPM4 in activating $\beta$-catenin signaling through inhibition of GSK-3 $\beta$ in prostate cancers. It was also reported that in addition to reduced cellular proliferation, shRNA-mediated knockdown of TRPM4 in PC3 cells displayed a decrease in SOCE (Sagredo et al., 2018) in contrast with earlier independent findings (Holzmann et al., 2015) where siRNA-mediated knockdown of TRPM4 in PC3 cells did not display defects in proliferation nor SOCE. Hence, the precise role of TRPM4 in regulating SOCE in prostate cancer cells needs to be confirmed by future independent studies.

Gene expression profiling also identified upregulation of TRPM4 transcripts in cervical cancer (Narayan et al., 2007) and DLBCL (Suguro et al., 2006). We recently demonstrated that TRPM4 protein was expressed in approximately $26 \%$ of DLBCL cases $(n=49 / 189)$ which conferred significantly poorer OS $(p=0.004)$ and progression-free survival (PFS) $(p=0.005)$. TRPM4 expression was absent in non-malignant B-cell populations in lymphoid tissues (reactive tonsil, lymph node, appendix) (Loo et al., 2017), suggesting that the ion channel to be abnormally upregulated in malignant B cells of DLBCL. Taken together, the existing evidence suggests that TRPM4 overexpression is associated with tumor progression and aggressiveness, although further studies are required to establish this, particularly in B-cell malignancies.

Recently, the atomic-level structure of TRPM4 was revealed through cryo-EM by four independent groups. The transmembrane domain of TRPM4 contains a $\mathrm{Ca}^{2+}$ binding site, and ATP is capable of binding its N-terminal nucleotide-binding domain (NBD), subsequently inhibiting TRPM4 activity (Autzen et al., 2018; Duan et al., 2018b; Guo et al., 2017; Winkler, Huang, Sun, Du, \& Lu, 2017). These detailed atomic-level maps of TRPM4 are required to facilitate future development of additional specific TRPM4 inhibitors that might act through 
selectively obstructing its $\mathrm{Ca}^{2+}$-activation binding site or induce TRPM4 inhibition through NBD binding, providing expanded avenues to target TRPM4 in relevant diseases including cancer..

\subsection{TRPM5: A Potential Oncochannel in Melanoma}

Similar to its structurally closest TRPM family member (i.e. TRPM4), TRPM5 is a monovalent cation-selective channel (permeable to $\mathrm{Na}^{+}, \mathrm{K}^{+}$) activated by increased $\left[\mathrm{Ca}^{2+}\right]_{i}$ but itself is impermeable to $\mathrm{Ca}^{2+}$. The ion channel is a taste signaling receptor for response to sweet, bitter and umami taste (Damak et al., 2006). TRPM5 is also expressed in olfactory epithelium where it is required to trigger responses to odorants and pheromones (Lemons et al., 2017). Additionally, TRPM5 is present in pancreatic cells where it promotes insulin secretion and TRPM5 SNPs are associated with increased prediabetic phenotypes including plasma glucose, defects in insulin secretion, and decreased insulin sensitivity (Vennekens, Mesuere, \& Philippaert, 2018). Induction of TRPM5 through the sweetening food additive steviol glycosides (SGs) has recently been proposed to treat type 2 diabetes (Philippaert et al., 2017). SGs potentiate TRPM5 channel activities that subsequently activate glucose-induced insulin secretion from pancreatic islets, and long-term SGs consumption prevents development of high-fat-diet-induced diabetes in mice in a TRPM5-dependent manner (Philippaert et al., 2017).

TRPM5 mRNA was found to be highly expressed in Wilms' tumor and rhabdomyosarcoma (Prawitt et al., 2000). In contrast, TRPM5 transcript was significantly lower in bladder cancer tissues compared to normal bladder $(p=0.003)$ but TRPM5 protein was not detected in the bladder tissues of either cancer patients or control subjects (Ceylan et al., 2016). Additionally, SNP present in TRPM5 (CG or GG genotype of rs2301696; intron) was reported to be significantly associated with decreased risk of childhood leukemia compared with the CC genotype ( $p=0.004)$ (Han et al., 2012).

In publicly-available databases, high TRPM5 mRNA expression was significantly associated with shorter survival in melanoma $(p<0.05)$ and gastric cancer $(p<0.001)$ patients although such association was not observed in ovarian, lung, breast and rectal cancers (Maeda et al., 2017). Acidic extracellular $\mathrm{pH}\left(\mathrm{pH}_{e}\right)$ is required for matrix metalloproteinase-9 (MMP9) expression and in the same study, the authors demonstrated that Trpm5 silencing in mouse melanoma cells (B16-BL6) reduced acidic $\mathrm{pH}_{e}$-induced expression of MMP9, decreased cellular elongation into 
fibroblastic shape associated with epithelial-mesenchymal transition (EMT), and C57BL/6 mice injected with B16-BL6 cells overexpressing Trpm5 showed increased lung metastasis. Tumorbearing mice treated with triphenylphosphine oxide (TPPO), an inhibitor of TRPM5 with IC $\mathrm{C}_{50}$ of $12 \mu \mathrm{M}$ (Palmer et al., 2010), exhibited decreased NF-kB activities and expression of EMTassociated genes (Mmp9, Vim, Cdh2) and reduced spontaneous lung metastasis, indicating the potential to target TRPM5 for metastasis prevention in melanoma (Maeda et al., 2017).

\subsection{TRPM6: Association with Neuroblastoma and Breast Cancer}

TRPM6 is a channel kinase with a TRP channel permeable to $\mathrm{Mg}^{2+}$ or $\mathrm{Ca}^{2+}$, and a carboxylterminal $\alpha$-kinase domain. The channel is activated by depletion of $\mathrm{Mg}^{2+}$ ions or autophosphorylation of its Ser/Thr-rich kinase domain (Clark et al., 2008). TRPM6 plays crucial roles in maintaining body magnesium homeostasis, as it is required for magnesium absorption in the intestine and active reabsorptions in the kidneys (Chubanov, Gudermann, \& Schlingmann, 2005; Voets et al., 2004). It has been recently shown that maintenance of $\mathrm{Mg}^{2+}$ balance by Trpm6 is vital for prenatal development and survival to adulthood in mice (Chubanov et al., 2016). TRPM6 mutations cause familial hypomagnesemia with secondary hypocalcemia, and abnormal renal magnesium excretion (Katayama et al., 2015; Walder et al., 2002) as well as insulin resistance (Nair et al., 2012).

TRPM6 transcripts were expressed in human neuroblastomas and siRNA-mediated downregulation of TRPM6 inhibited proliferation of neuroblastoma cell line (SHEP-21N) (Zhang et al., 2014a). TRPM6 transcripts were expressed at low levels in the colon cancer cell line HT29, and siRNA-mediated knockdown of TRPM6 in these cells did not show any effects on cell proliferation, in contrast to TRPM7 knockdown (Huang et al., 2017b). The authors concluded that TRPM7, rather than TRPM6, played the dominant role in $\mathrm{Mg}^{2+}$ transport in HT-29 cells based on the data of their siRNA knockdown, pharmacological inhibition (waixenicin A) of TRPM7, and measurement of TRPM7-like currents.

In addition, TRPM6 mutation (p.R1122Q) affecting its topological domain towards the cytoplasm occurs in a small proportion of breast cancer patients (Zhang et al., 2015), and two other TRPM6 somatic mutations (p.T1822A and p.A1765T) have also been observed in an independent cohort of breast cancer samples (Stephens et al., 2012). TRPM6 missense 
mutation (p.P1099L) was also reported in a metastatic triple-negative breast cancer patient without hereditary BRCA1, BRCA2, or TP53 risk variants, and its expression was reduced by half compared with healthy controls (Meissner et al., 2017). The roles of TRPM6 in breast cancer cells have not been examined and it is unclear whether TRPM6 mutations represent loss- or gain-of-function mutations.

A potential issue that might complicate interpretation of loss-of-function or expression is the ability of some of these channels to form heteromers and in this particular case, the heteromic TRPM6/TRPM7 (TRPM6/7) channel. TRPM6/7 can form heteromers when they are activated by reduced concentrations of intracellular $\mathrm{Mg}^{2+}$ and $\mathrm{Mg} \cdot \mathrm{ATP}$, and TRPM6/7-mediated $\mathrm{Mg}^{2+}$ influx is indispensable in human epithelial colon cells (Ferioli et al., 2017; Luongo et al., 2018; Zhang et al., 2014b). In human neuroblastoma cells (SHEP-21N), endogenous TRPM6/7 heteromer currents showed diminished sensitivity to 2-aminoethoxydiphenyl borate (2-APB; an ion channel inhibitor) and that N-Myc-induced expression of heteromeric TRPM6/7 channels promoted $\mathrm{Ca}^{2+}$ and $\mathrm{Mg}^{2+}$ uptake (Zhang et al., 2014a). siRNA-mediated reduction of TRPM6/7 expression inhibited cell proliferation, indicating the oncogenic properties of TRPM6/7 heteromer (Zhang et al., 2014a). Such heteromerization leads to further functional diversification and assessment of both TRPM6 and TRPM7 oncogenic properties might also need to consider the presence and relevance of TRPM6/7 heteromers especially when both channels are expressed in the same cancer cells.

\subsection{TRPM7: An Oncochannel in Numerous Cancer Types}

TRPM7, the closest homologue to TRPM6, is also another channel kinase that enables the entry of $\mathrm{Mg}^{2+}$ and $\mathrm{Ca}^{2+}$, and it is crucial for magnesium absorption (Ryazanova et al., 2010). Apart from maintaining whole body $\mathrm{Mg}^{2+}$ homeostasis, TRPM7 plays diverse roles including axonal growth and maturation of hippocampal neurons (Turlova et al., 2016), mediates the mineralization of craniofacial hard tissues (Nakano et al., 2016), as well as regulating mast cell degranulation and release of histamine through its kinase activity (Zierler et al., 2016).

TRPM6 and TRPM7 are unique in that they are the only known dual-function ion channels and contain an a-type (i.e. atypical with low homology to conventional protein kinases) serine/threonine protein kinase domain (channel kinase or chanzyme) (Chubanov, Mittermeier, 
480

481

482

483

484

485

486

487

488

489

490

491

492

493

494

495

496

497

498

499

500

501

502

503

504

505

506

507

508

509

510

511

\& Gudermann, 2018). The channel and kinase domains are functionally connected whereby in TRPM6, the activated channel domain triggers cleavage of the kinase domain and the freed kinase is transported into the nucleus to phosphorylate specific histone residues critical for cell differentiation and embryonic development (Krapivinsky et al., 2017). Mice heterozygous for TRPM7 kinase deletion demonstrated reduced channel activity and hypomagnesemia (Ryazanova et al., 2010), and its kinase activity regulates stability and localization of the channel in epithelial cells (Cai, Lou, Al-Saadi, Tetteh, \& Runnels, 2018). The functional connection between both domains has introduced difficulties in interpreting the precise mechanisms regulating the functions of TRPM6 or TRPM7. For instance, the impact of TRPM7 kinase activity on T-cell proliferation efficiency has remained controversial (Nadolni, \& Zierler, 2018), and TRPM7's kinase domain has also been reported to operate independently of its channel activity when it plays a vital role in ameloblast (i.e. enamel-depositing cells present during tooth development) differentiation via phosphorylation of CREB (Ogata et al., 2017).

Of all TRPM family members, the oncogenic roles of TRPM7 have been the most widely documented. Suppression of TRPM7 via siRNA reduced proliferation, migration and invasion capabilities of malignant human glioma cells (A172) along with decreasing TRPM7-like ion currents (Leng et al., 2015). Conversely, treatment of glioblastoma cells (U87) with naltriben, a pharmacological activator of TRPM7, induced TRPM7-like current via $\mathrm{Ca}^{2+}$ influx, and enhanced migration and invasion but not viability and proliferation of U87 cells. These were in conjunction with increased activation of proteins involved in MAPK/ERK but not of PI3K/AKT signaling pathway (Wong, Turlova, Feng, Rutka, \& Sun, 2017).

In aggressive PDAC cells (PANC-1 and MIA PaCa-2), TRPM7 mediated the entry of $\mathrm{Mg}^{2+}$ and was required for cell invasion without effects on cell viability as shown by TRPM7 knockdown by siRNA or shRNA (Rybarczyk et al., 2017). $\mathrm{Mg}^{2+}$ entry was reported to be associated with the invasiveness of these cells and MMP secretions, and higher expression levels of TRPM7 in primary human PDAC tumors were associated with metastasis of PDAC cells that disseminated from the pancreas to lymph node. The authors proposed that $\mathrm{Mg}^{2+}$ entry induced heat-shock protein 90a (Hsp90a) secretion that in turn stabilized both pro-MMP2 and urokinase plasminogen activator (UPA) pathway that subsequently promoted degradation of extracellular matrix (ECM) and PDAC cell invasiveness. 
513 In breast cancers, higher TRPM7 mRNA levels were associated with significantly inferior 514 recurrence-free survival $(p=0.042)$ and distant metastasis-free survival $(p=0.003)$, and were 515 required for the proliferation and metastasis of human breast cancer cells (MDA-MB-231) in 516 xenografts (immunodeficient Rag2 ${ }^{-/} / L 2 \mathrm{rg}^{-/-}$mice) (Middelbeek et al., 2012). Recently, TRPM7 517 has been shown to maintain the mesenchymal phenotype of breast cancer cell lines (MDA-MB-

518231 and Hs 578T) by reducing cytoskeletal tension and suppression of myosin II activity that in 519 turn activates expression of the EMT transcription factor SOX4, suggesting TRPM7-mediated 520 mechanical activation of SOX4 contributes to breast cancer metastasis (Kuipers et al., 2018). 521 Similarly in prostate cancer, TRPM7 was required for TGF $\beta$-induced EMT (e.g. increased 522 expression of vimentin) that subsequently promoted invasion of DU145 and PC3 cells (Sun, 523 Schaar, Sukumaran, Dhasarathy, \& Singh, 2018a). These findings were also similar with those 524 observed by an independent group (Chen et al., 2017) where TRPM7 knockdown showed 525 decreased migration of prostate cancer cells (DU145 and PC3), while its overexpression showed the opposite, and also with reduced or increased expression of EMT activator (MMP2 and MMP9) or suppressor (E-cadherin) proteins, respectively.

For other cancer types, readers are directed to a recent review on TRPM7 in malignancies 530 (Yee, 2017). Collectively, TRPM7 plays multiple oncogenic roles in various cancers particularly via inducing metastasis, establishing it as a promising oncological therapeutic target. In addition,

532 the closed state structures of mouse TRPM7 have recently been resolved by cryo-EM where the 533 key residues for ion binding and formation of disulfide bond within the pore helix have been 534 uncovered (Duan et al., 2018a).

535

\subsection{TRPM8: Oncogenic Cytoplasmic Localization and Short Isoforms}

537 TRPM8 is a thermally-regulated ion channel (permeable to $\mathrm{Ca}^{2+}, \mathrm{Na}^{+}, \mathrm{K}^{+}$) that it is activated by 538 cold temperatures and chemical cooling compounds such as menthol and eucalyptol (Liu et al., 539 2013). Its roles in somatosensory neurons have been well-established where it primarily 540 functions to detect cold temperatures (Bautista et al., 2007) and is responsible for normal eye541 blinking in mice (Quallo et al., 2015). In addition, TRPM8 is highly expressed in prostate tissues 542 where the ion channel functions as testosterone receptor, suggesting a role in regulating 543 androgen responses (Asuthkar et al., 2015a). 
545

546

547

548

549

550

551

552

553

554

555

556

557

558

559

560

561

562

563

564

565

566

567

568

569

570

571

572

573

574

575

Activities of TRPM8 were required for the chemotaxis and migration of glioblastoma cells (T98G and $\mathrm{U}-87 \mathrm{MG}$ ) as shown by siRNA-mediated downregulation of TRPM8, pharmacological inhibition by the TRP channel blocker BCTC or TRPM8 activation by icilin (Klumpp et al., 2017). The authors reported that TRPM8 induced migration of these glioblastoma cells possibly through activation of $\mathrm{Ca}^{2+}$-regulated $\mathrm{K}^{+}$channel i.e. big conductance $(\mathrm{BK}) \mathrm{K}^{+}$channel. The same study also demonstrated that TRPM8 conferred resistance to ionizing radiation and survival of U251 glioblastoma cells. TRPM8 contributed to S phase progression of the cell cycle and mitosis of glioblastoma cells via induction of CaMKII isoforms, cdc25C (phosphatase) and cdc2 (cyclin-dependent kinase) (Klumpp et al., 2017).

Several lines of evidence have demonstrated TRPM8 to have important functions in the development and progression of tumors, and it is an emerging therapeutic target particularly in prostate cancer. TRPM8 is overexpressed in prostate tumors compared to non-malignant prostate tissues, and the protein is present in hormone-refractory prostate cancer and in cases with higher Gleason scores (Yee, 2015). TRPM8 depletion inhibited proliferation of prostate cancer cells (LNCaP and PC3) and promoted their chemosensitivity towards epirubicin via increased phosphorylation of p38 and JNK proteins (Liu et al., 2018b). It was shown that TRPM8 protein, internalized from its normal plasma membrane localization, was degraded in prostate cancer cells (LNCaP) via proteasomal and lysosomal pathways (Asuthkar, Demirkhanyan, Mueting, Cohen, \& Zakharian, 2017; Asuthkar, Velpula, Elustondo, Demirkhanyan, \& Zakharian, 2015b). A higher degree of TRPM8 internalization and degradation correlated with increased severity of human prostate cancer cases. The authors proposed restoration of plasma membrane TRPM8 expression to be a potential therapeutic strategy.

Moreover, independent groups of researchers demonstrated that TRPM8 short isoforms localized in the cytoplasm (in contrast to the full-length TRPM8 localized on the plasma membrane) were required for the survival, migration and invasion of prostate cancer cells (LNCaP) (Bidaux et al., 2016; Peng et al., 2015). Multiple non-channel cytoplasmic TRPM8

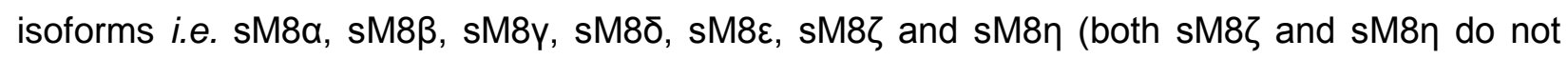
encode protein), collectively termed as SM8, were found to be expressed in prostate cancer cell lines (PC3, LNCaP and LNCaP C4-2b) (Bidaux et al., 2016). Concomitant knockdown of full- 
576 length TRPM8 and SM8 induced apoptosis of the androgen-refractory prostate cancer cells 577 LNCaP C4-2b. The apoptosis phenotype was achieved through induction of endoplasmic 578 reticulum $(E R)$ stress, oxidative stress of the mitochondria and promotion of p21 (a protein that 579 restricts cell cycle) expression. These mechanisms required the activity of 4TM-TRPM8 580 (another truncated TRPM8 isoform consisting of four transmembrane domains which localized 581 in the ER membranes instead of the plasma membrane) at the ER-mitochondria junction 582 (Bidaux et al., 2016).

583

584 TRPM8 was also significantly overexpressed in osteosarcoma at both mRNA and protein levels 585 associated with higher clinical stage $(p=0.007)$, distant metastasis $(p=0.030)$, worse oS $586(p=0.008)$ and DFS ( $p=0.008)$ (Zhao, \& Xu, 2016). In addition, TRPM8 appears to play important 587 roles in the following other cancer types:

588 (i) In pancreatic cancer, where TRPM8 silencing induced replicative senescence of pancreatic 589 adenocarcinoma cell lines BxPC-3 and PANC-1 (Yee et al., 2012);

(ii) TRPM8 was highly expressed in breast cancer cell lines compared to normal breast 592 epithelial cells and the protein promoted breast cancer metastasis (Liu et al., 2014). Notably, 593 TRPM8 channel activity in breast cancer might be hormone-dependent. TRPM8 expression was 594 regulated by estrogen receptor alpha (ERa) and estrogens in MCF7 cell line, and its 595 overexpression in breast adenocarcinoma correlated with estrogen receptor status of the tumors 596 (Chodon et al., 2010). However, a recent study (Yapa et al., 2018) demonstrated that TRPM8 597 was not expressed in MDA-MB-231 cells, and the authors highlighted that applicability of 598 TRPM8 as a therapeutic target in breast cancers might be limited due to absence of TRPM8 599 transcript in four of seven (57.1\%) breast cancer cell lines investigated;

600

601 (iii) Menthol-induced TRPM8 augmented the migration and invasion capabilities of oral 602 squamous carcinoma cell lines, HSC3 and HSC4 (Okamoto, Ohkubo, Ikebe, \& Yamazaki, 603 2012). Conversely, TRPM8 was expressed in the human bladder cancer cells (T24) and 604 induction of TRPM8 activity by menthol promoted death of T24 cells (Li, Wang, Yang, Wang, \& $605 \mathrm{Li}, 2009)$. These apparent opposing roles of TRPM8 might be due to the differential expression 606 of TRPM8 full-length or isoforms, and it warrants future investigations. 
608

609

610

611

612

613

614

615

616

617

618

619

620

621

622

623

624

625

626

627

628

629

630

631

632

633

634

635

636

637

638

639

The cryo-EM structure of the full-length TRPM8 derived from collared flycatcher has recently been revealed whereby the binding site for its activator menthol is located within a voltagesensor-like domain, providing molecular cues of cold and menthol sensation (Yin et al., 2018).

\section{INHIBITORS OF TRPM CHANNELS}

TRPM1 currents in retinal ON-bipolar cells are activated by application of capsaicin. Voriconazole, an antifungal triazole, has been shown to cause transient visual disturbances by blocking capsaicin-activated currents in mice ON-bipolar cells (injected with $0.24 \mathrm{mg} / \mathrm{g}$ body weight voriconazole; $90 \pm 4 \%$ inhibition). The authors have been unable to test the effects of voriconazole directly on TRPM1 channels due to the difficulty with heterologous expression of TRPM1 but instead demonstrated that voriconazole inhibited TRPM3 (92.3 $\pm 6.3 \%$ inhibition), the most closely related channel to TRPM1 with $70 \%$ amino acid sequence identity, hence concluded that voriconazole could block both TRPM1 and TRPM3 (Xiong et al., 2015).

In terms of TRPM2 inhibitors, the plant-derived polyphenol in turmeric spice, curcumin, inhibited TRPM2-mediated elevation of cytosolic $\left[\mathrm{Ca}^{2+}\right]$ in rat hepatocytes suggesting that the hepatoprotective effects of curcumin from oxidative stress might be partially attributable to inhibition of TRPM2 channel activities (Kheradpezhouh, Barritt, \& Rychkov, 2016). The authors also reported that curcumin inhibited activation of TRPM2 in HEK293T cells overexpressing human TRPM2 ( $\left.\mathrm{IC}_{50}:-50 \mathrm{nM}\right)$. The anti-tumor properties of curcumin have been welldocumented and it inhibits numerous cancer cell signaling pathways including NF-KB, STAT3, $\mathrm{PI3K} / \mathrm{AKT} / \mathrm{mTOR}$, and $\mathrm{Wnt} / \mathrm{\beta}$-catenin pathways, furthermore it potentiates the effects of chemotherapeutic agents and radiation against multiple tumor types (Li et al., 2018; Liu, Wang, \& Li, 2018a; Tian et al., 2017). This nutraceutical is capable of interacting with the targets modulated by a wide variety of FDA-approved drugs against cancer (Kunnumakkara et al., 2017), and TRPM2 is thus unlikely to be its sole target in cancer cells that express high levels of TRPM2.

The multitarget feature of curcumin also includes non-coding RNAs including microRNAs (18-22 nucleotides long) (Lelli, Pedone, Majeed, \& Sahebkar, 2017) and IncRNAs (>200 nucleotides long) where it inhibits the expression of specific IncRNAs in pancreatic cancer cells (Yoshida, Toden, Ravindranathan, Han, \& Goel, 2017) and lung cancer cells (Wang et al., 2018b). Apart 
640

641

642

643

644

645

646

647

648

649

650

651

652

653

654

655

656

657

658

659

660

661

662

663

664

665

666

667

668

669

670

from directly inhibiting the channel activity of TRPM2, examining the potential of curcuminmediated downregulation of the oncogenic TRPM2-AS could be of interest. Other TRPM2 inhibitors are as follows: (i) 2-APB inhibited the activities TRPM2 channels in TRPM2overexpressing HEK293 cells (IC50: 1UM), and the compound also inhibited insulin release from rat pancreatic cells (Togashi, Inada, \& Tominaga, 2008); (ii) Scalaradial (a type of sesterterpene derived from marine natural product) inhibited TRPM2-mediated $\mathrm{Ca}^{2+}$ influx in HEK293 cells overexpressing TRPM2 (IC $50: 210 \mathrm{nM})$ and the endogenous currents of rat insulinoma cells (INS-1; IC 50 : $330 \mathrm{nM}$ ); (iii) In a 3D similarity-based virtual screening, a ligandbased virtual screening methodology, the 2,3-dihydroquinazolin-4(1H)-one derivative $\mathrm{H} 1$ was shown to be a novel TRPM2 inhibitor and the authors subsequently synthesized a variety of $\mathrm{H} 1$ derivatives where one of its derivatives, compound D9, yielded the most potent TRPM2 inhibition in TRPM2-overexpressing HEK293 cells ( $\mathrm{IC}_{50}$ : $\left.3.7 \mu \mathrm{M}\right)$; (iv) A series of adenosine 5'diphosphoribose analogues were screened for their inhibitory properties against TRPM2, and two compounds namely $7 \mathrm{i}$ and $8 \mathrm{a}$ were shown to be specific TRPM2 inhibitors (IC $50: 5.7$ and 5.4 $\mu \mathrm{M}$, respectively).

Non-steroid anti-inflammatory drugs (NSAIDs) used for pain treatment demonstrate inhibitory activity against TRPM3. These include mefenamic acid shown to inhibit TRPM3-mediated $\mathrm{Ca}^{2+}$ entry in TRPM3-overexpressing HEK293 cells (IC $50: 6.6 \pm 1.8 \mu \mathrm{M})$ as well as endogenous TRPM3 in the insulin-secreting INS-1E cells (Klose et al., 2011). Diclofenac represents another NSAID that inhibits TRPM3 where it inhibited TRPM3-dependent $\mathrm{Ca}^{2+}$ responses in HEK293 cells expressing the longest human TRPM3 isoform (TRPM3-9; IC 50 : $7.1 \mu \mathrm{M}$ ) and human neuroblastoma IMR-32 cells ( $\left.\mathrm{IC}_{50}: 17.1 \mu \mathrm{M}\right)$. The anticonvulsant of barbiturate class, primidone, has also been shown to inhibit TRPM3 where $\mathrm{Ca}^{2+}$ influx via TRPM3 was inhibited by primidone in TRPM3-overexpressing HEK293 cells $\left(\mathrm{IC}_{50}: 0.6 \pm 0.15 \mu \mathrm{M}\right)$ at concentrations lower than plasma concentrations used in antiepileptic therapy (Krugel, Straub, Beckmann, \& Schaefer, 2017). TRPM3 could also be inhibited by plant-derived compounds including citrus fruit flavanones, and screening with a library of chemically-related compounds demonstrated that isosakuranetin and liquiritigenin harbored TRPM3 inhibitory properties $\left(\mathrm{IC}_{50}\right.$ : $50 \pm 6 \mathrm{nM}$ and $500 \pm 70 \mathrm{nM}$, respectively) (Straub et al., 2013). 
671 The phenanthrene derivative compound 9-phenanthrol has been the most commonly used 672 TRPM4 inhibitor to investigate the ion channel's roles in physiology and autoimmune or 673 cardiovascular diseases, however it lacks potency with a reported $\mathrm{IC}_{50}$ of $20 \mu \mathrm{M}$ (Grand et al., 674 2008). Flufenamic acid (FFA) and glibenclamide have also been shown to inhibit TRPM4 but 675 both compounds have yielded even lower potency or specificity than 9-phenanthrol (Guinamard, 676 Hof, \& Del Negro, 2014). Recently, fluorescence cell-based screening assay to monitor TRPM4677 induced $\mathrm{Na}^{+}$influx has been utilized to screen for TRPM4-specific inhibitors through a ligand678 based virtual screening approach of a catalog of 900,000 compounds available commercially to 679 uncover analogs of 9-phenanthrol, FFA and glibenclamide (Ozhathil et al., 2018). The authors 680 found aryloxyacyl-anthranilic 5 (compound 5) to be the most potent and specific TRPM inhibitor $681\left(\mathrm{IC}_{50}: 1.5 \pm 0.1 \mu \mathrm{M}\right)$ with 20 times stronger inhibition than 9-phenanthrol $\left(\mathrm{IC}_{50}=29.1 \pm 5.8 \mu \mathrm{M}\right)$. 682 Compound 5 also inhibited endogenous TRPM4 currents in prostate cancer cells (LNCaP; IC 50 : $6831.1 \pm 0.3 \mu \mathrm{M})($ Ozhathil et al., 2018), underscoring the need for future research on its therapeutic 684 685 potential in prostate cancers known to overexpress functional TRPM4 proteins as discussed previously.

686

687 Triphenylphosphine oxide (TPPO) was identified as a selective inhibitor of TRPM5 in both 688 human $\left(\mathrm{IC}_{50}: 12 \mu \mathrm{M}\right)$ and murine TRPM5 (IC $\left.50: 30 \mu \mathrm{M}\right)$. In an in vitro kinome screen followed by 689 loss-of-function experiments, mesendogen, a compound that disrupts human embryonic stem 690 cell (hESC) pluripotency by inducing mesoderm and definitive endoderm differentiation (Geng et 691 al., 2015), has been identified to inhibit TRPM6 in hESCs (effective mesendogen concentration 692 tested: $10 \mu \mathrm{M}$ ). Our literature searches did not yield information on other inhibitors with $\mathrm{IC}_{50} \leq 10$ $693 \mu \mathrm{M}$ for TRPM1, TRPM5 or TRPM6, thus voriconazole (inhibited capsaicin-activated currents in 694 mice ON-bipolar cells), TPPO $\left(\mathrm{IC}_{50}>10 \mu \mathrm{M}\right)$, and mesendogen (effective concentration was 695 reported instead of $\mathrm{IC}_{50}$ ) against each TRPM channel, respectively, were included in this review. 696

697 In an aequorin bioluminescence-based assay, the compound NS8593 was identified to be a 698 potent TRPM7 inhibitor (IC $50: 1.6 \mu \mathrm{M})$, in TRPM7-overexpressing HEK293 cells, that disrupted $699 \mathrm{Mg}^{2+}$ fluxes and interrupted TRPM7-like currents in a variety of cell types including smooth 700 muscle cells, primary podocytes and ventricular myocytes (Chubanov et al., 2012). In the 701 context of cancer cells, a TRPM7 kinase assay was performed to identify potent TRPM7 702 inhibitors in breast cancer cells known to require TRPM7 for proliferation, invasion and 
703

704 705

706

707

708

709

710

711

712

713

714

715

716

717

718

719

720

721

722

723

724

725

726

727

728

729

730

731

732

733

734

metastasis (Song et al., 2017). TG100-115 was identified to inhibit TRPM7 (IC50: $1.96 \mu M$ ) in MDA-MB-231 breast cancer cells that also decreased cell migration and invasion.

A marine-based compound isolated from Hawaiian soft coral blocks Sarcothelia edmondsoni, waixenicin A, was identified as a specific TRPM7 inhibitor through high-throughput assays of chemical library derived from 1,100 marine organism extracts (Zierler et al., 2011). Waixenicin A inhibited TRPM7 in TRPM7-overexpressing HEK293 cells $\left(\mathrm{IC}_{50}: 7 \mu \mathrm{M}\right)$ and blocked native TRPM7 conductance in T-cell lymphoma cells (Jurkat) as well as reduced the cell cycle progression of Jurkat cells. In human colon cancer cells (HT-29), waixenicin A inhibited TRPM7 currents $\left(\mathrm{IC}_{50}: 3.1 \mu \mathrm{M}\right)$ and disrupted cell proliferation, and its administration caused hypomagnesemia in mice models through insufficient absorption of $\mathrm{Mg}^{2+}$ in the colon.

AMTB, a form of hydrochloride salt, is the most commonly used TRPM8 inhibitor and this disrupted $\mathrm{Ca}^{2+}$ influx through activated TRPM8 channel in HEK293 cells expressing TRPM8 (pIC ${ }_{50}: 6.23$ equivalent to $\mathrm{IC}_{50}: 0.589 \mu \mathrm{M}$ ) (Lashinger et al., 2008). However, it has recently been shown that AMTB could inhibit specific voltage gated sodium channels (Nav channels) in breast cancer cells that lacked TRPM8 expression (Yapa et al., 2018). Other potent TRPM8 inhibitors that have been uncovered are as follows: (i) A form of carbamate hydrochloride was shown to inhibit TRPM8 in TRPM8-overexpressing HEK293 cells (IC 50 : 15.6 nM); (ii) A compound termed AMG2850 was found to inhibit TRPM8 in TRPM8-overexpressing Chinese hamster ovary (CHO) cells ( $\left.\mathrm{IC}_{50}: 41 \pm 8 \mathrm{nM}\right)$.

As one of the sentinels of human sensations, TRPM family of proteins are receptive to a relatively wide range of natural or synthetic chemical compounds, a similar phenomenon recognized in other TRP ion channels (Vriens, Nilius, \& Vennekens, 2008). While this broadens the avenues available to target TRPM channels, identifying inhibitors that specifically target an individual TRPM channel without off-target effects on its closest family member (e.g. TRPM4 and TRPM5) or on other non-TRP ion channels with similar pharmacological properties (e.g. ability to interact with compounds of similar chemical structures) poses a challenge due to a multitude of ion channels being present. Development of focused assays to test the specificity of inhibitors against a large set of ion channels, or uncovering specific inhibitors with $\mathrm{IC}_{50}$ at low nanomolar concentrations is thus recommended. Furthermore, assessing inhibitors against 
endogenous TRPM channels in addition to heterologous overexpression system, which has dominated most of the assessed inhibitors (Table 1), is evidently desirable.

\section{CONCLUSIONS}

Accumulating evidence indicates that TRPM channels could serve as promising targets for cancer therapy. Herein, we summarize that TRPM2-AS, TRPM3, TRPM4, TRPM5, TRPM7, or TRPM8 isoforms (Figure 2 and Figure 3) represent promising therapeutic targets in human malignancies where multiple lines of evidence have reported their overexpression in cancers and functional proof of their requirement for cancer cell growth, survival, invasion and/or EMT.

The main weaknesses of the studies discussed in this review are as follows: (1) TRPM proteins are widely expressed in different human organs with various normal physiological roles. Thus, modulating TRPM channel activity could alter intracellular cation levels that may in turn negatively impact cellular function and confer normal organ toxicities. However, TRPM2-AS and TRPM8 isoforms might have more restricted expression in non-malignant human organs, and thus might represent more specific targets; (2) Certain studies have not measured changes in ion fluxes or intracellular ion concentrations on modulating the activities of specific TRPM channel nor measuring changes in the specific TRPM current. This is required to confirm that the phenotypes observed (e.g. cell proliferation, migration, EMT) are directly attributable to the reduced or increased TRPM activities following pharmacological inhibition, knockdown, knockout or overexpression methodologies.

Finally, within the past 1-2 years, major discoveries have been made in resolving the structures of TRPM2, TRPM4, TRPM7 and TRPM8 through cryo-EM. Due to the advancement and higher adoption of cryo-EM methodologies in resolving complex receptors' or the structure of ion channels' embedded in the plasma membrane, it is conceivable that the structures of other TRPM channels are currently being resolved. These data should aid in upcoming drug design with domain-specific inhibitory activities and precise mode-of-action, expanding the potential to target TRPM oncochannels, as demonstrated by various functional proofs of their oncogenic properties, for the destruction of human cancer cells. 


\section{ACKNOWLEDGEMENTS}

We would like to thank the staff members at Department of Immunology, School of Medical Sciences, Universiti Sains Malaysia for supporting our work. This work has been supported by Research University grant (1001/PPSP/813054) awarded to KKW.

\section{CONFLICTS OF INTEREST}

All authors declare that there are no conflicts of interest.

\section{AUTHORS' CONTRIBUTIONS}

KKW conceived and designed the manuscript, conducted literature searches, made the figures, prepared the table and wrote the manuscript. AHB and NSY critically edited the manuscript and conducted literature searches. SMNH made a figure, prepared the table and conducted literature searches. All authors read and approved the final manuscript.

\section{REFERENCES}

Almasi, S., Kennedy, B. E., El-Aghil, M., Sterea, A. M., Gujar, S., Partida-Sanchez, S., El Hiani, Y. (2018). TRPM2 channel-mediated regulation of autophagy maintains mitochondrial function and promotes gastric cancer cell survival via the JNK-signaling pathway. The Journal of biological chemistry, 293(10), 3637-3650.

Arcangeli, A., Becchetti, A., Mannini, A., Mugnai, G., De Filippi, P., Tarone, G., . . Olivotto, M. (1993). Integrin-mediated neurite outgrowth in neuroblastoma cells depends on the activation of potassium channels. The Journal of cell biology, 122(5), 1131-1143.

Asuthkar, S., Demirkhanyan, L., Mueting, S. R., Cohen, A., Zakharian, E. (2017). High-throughput proteome analysis reveals targeted TRPM8 degradation in prostate cancer. Oncotarget, 8(8), 12877-12890.

Asuthkar, S., Elustondo, P. A., Demirkhanyan, L., Sun, X., Baskaran, P., Velpula, K. K., . . Zakharian, E. (2015a). The TRPM8 protein is a testosterone receptor: I. Biochemical evidence for direct TRPM8-testosterone interactions. The Journal of biological chemistry, 290(5), 2659-2669.

Asuthkar, S., Velpula, K. K., Elustondo, P. A., Demirkhanyan, L., Zakharian, E. (2015b). TRPM8 channel as a novel molecular target in androgen-regulated prostate cancer cells. Oncotarget, 6(19), 1722117236.

Autzen, H. E., Myasnikov, A. G., Campbell, M. G., Asarnow, D., Julius, D., Cheng, Y. (2018). Structure of the human TRPM4 ion channel in a lipid nanodisc. Science, 359(6372), 228-232.

Bao, L., Chen, S. J., Conrad, K., Keefer, K., Abraham, T., Lee, J. P., . . Miller, B. A. (2016). Depletion of the Human Ion Channel TRPM2 in Neuroblastoma Demonstrates Its Key Role in Cell Survival through Modulation of Mitochondrial Reactive Oxygen Species and Bioenergetics. The Journal of biological chemistry, 291(47), 24449-24464.

Barbet, G., Demion, M., Moura, I. C., Serafini, N., Leger, T., Vrtovsnik, F., . . Launay, P. (2008). The calcium-activated nonselective cation channel TRPM4 is essential for the migration but not the maturation of dendritic cells. Nature immunology, 9(10), 1148-1156. 
Bautista, D. M., Siemens, J., Glazer, J. M., Tsuruda, P. R., Basbaum, A. I., Stucky, C. L., . . Julius, D. (2007). The menthol receptor TRPM8 is the principal detector of environmental cold. Nature, 448(7150), 204-208.

Berg, K. D., Soldini, D., Jung, M., Dietrich, D., Stephan, C., Jung, K., . . Kristiansen, G. (2016). TRPM4 protein expression in prostate cancer: a novel tissue biomarker associated with risk of biochemical recurrence following radical prostatectomy. Virchows Archiv : an international journal of pathology, 468(3), 345-355.

Bianchi, B., Ozhathil, L. C., Medeiros-Domingo, A., Gollob, M. H., Abriel, H. (2018). Four TRPM4 Cation Channel Mutations Found in Cardiac Conduction Diseases Lead to Altered Protein Stability. Front Physiol, 9177.

Bidaux, G., Borowiec, A. S., Dubois, C., Delcourt, P., Schulz, C., Vanden Abeele, F., . . Prevarskaya, N. (2016). Targeting of short TRPM8 isoforms induces 4TM-TRPM8-dependent apoptosis in prostate cancer cells. Oncotarget, 7(20), 29063-29080.

Brozyna, A. A., Guo, H., Yang, S. E., Cornelius, L., Linette, G., Murphy, M., . . Carlson, J. A. (2017). TRPM1 (melastatin) expression is an independent predictor of overall survival in clinical AJCC stage I and II melanoma patients. J Cutan Pathol, 44(4), 328-337.

Cai, N., Lou, L., Al-Saadi, N., Tetteh, S., Runnels, L. W. (2018). The kinase activity of the channel-kinase protein TRPM7 regulates stability and localization of the TRPM7 channel in polarized epithelial cells. The Journal of biological chemistry, 293(29), 11491-11504.

Cao, Q. F., Qian, S. B., Wang, N., Zhang, L., Wang, W. M., Shen, H. B. (2015). TRPM2 mediates histone deacetylase inhibition-induced apoptosis in bladder cancer cells. Cancer Biother Radiopharm, 30(2), 87-93.

Ceylan, G. G., Onalan, E. E., Kuloglu, T., Aydog, G., Keles, I., Tonyali, S., Ceylan, C. (2016). Potential role of melastatin-related transient receptor potential cation channel subfamily $\mathrm{M}$ gene expression in the pathogenesis of urinary bladder cancer. Oncology letters, 12(6), 5235-5239.

Chen, B., Ng, G., Gao, Y., Low, S. W., Sandanaraj, E., Ramasamy, B., . . L Liao, P. (2018). Non-Invasive Multimodality Imaging Directly Shows TRPM4 Inhibition Ameliorates Stroke Reperfusion Injury. Transl Stroke Res.

Chen, L., Cao, R., Wang, G., Yuan, L., Qian, G., Guo, Z., . . Xiao, Y. (2017). Downregulation of TRPM7 suppressed migration and invasion by regulating epithelial-mesenchymal transition in prostate cancer cells. Med Oncol, 34(7), 127.

Chodon, D., Guilbert, A., Dhennin-Duthille, I., Gautier, M., Telliez, M. S., Sevestre, H., Ouadid-Ahidouch, H. (2010). Estrogen regulation of TRPM8 expression in breast cancer cells. BMC Cancer, 10212.

Chubanov, V., Ferioli, S., Wisnowsky, A., Simmons, D. G., Leitzinger, C., Einer, C., . . Gudermann, T. (2016). Epithelial magnesium transport by TRPM6 is essential for prenatal development and adult survival. Elife, 5.

Chubanov, V., Gudermann, T., Schlingmann, K. P. (2005). Essential role for TRPM6 in epithelial magnesium transport and body magnesium homeostasis. Pflugers Arch, 451(1), 228-234.

Chubanov, V., Mederos y Schnitzler, M., Meissner, M., Schafer, S., Abstiens, K., Hofmann, T., Gudermann, T. (2012). Natural and synthetic modulators of SK (K(ca)2) potassium channels inhibit magnesium-dependent activity of the kinase-coupled cation channel TRPM7. British journal of pharmacology, 166(4), 1357-1376.

Chubanov, V., Mittermeier, L., Gudermann, T. (2018). Role of kinase-coupled TRP channels in mineral homeostasis. Pharmacol Ther, 184159-176.

Clark, K., Middelbeek, J., Morrice, N. A., Figdor, C. G., Lasonder, E., van Leeuwen, F. N. (2008). Massive autophosphorylation of the Ser/Thr-rich domain controls protein kinase activity of TRPM6 and TRPM7. PloS one, 3(3), e1876. 
Courboulin, A., Paulin, R., Giguere, N. J., Saksouk, N., Perreault, T., Meloche, J., . . Bonnet, S. (2011). Role for miR-204 in human pulmonary arterial hypertension. The Journal of experimental medicine, 208(3), 535-548.

Damak, S., Rong, M., Yasumatsu, K., Kokrashvili, Z., Perez, C. A., Shigemura, N., . . Margolskee, R. F. (2006). Trpm5 null mice respond to bitter, sweet, and umami compounds. Chem Senses, 31(3), 253-264.

Daumy, X., Amarouch, M. Y., Lindenbaum, P., Bonnaud, S., Charpentier, E., Bianchi, B., . . Schott, J. J. (2016). Targeted resequencing identifies TRPM4 as a major gene predisposing to progressive familial heart block type I. Int J Cardiol, 207349-358.

Deeds, J., Cronin, F., Duncan, L. M. (2000). Patterns of melastatin mRNA expression in melanocytic tumors. Human pathology, 31(11), 1346-1356.

Dembla, S., Behrendt, M., Mohr, F., Goecke, C., Sondermann, J., Schneider, F. M., . . Oberwinkler, J. (2017). Anti-nociceptive action of peripheral mu-opioid receptors by G-beta-gamma proteinmediated inhibition of TRPM3 channels. Elife, 6.

Duan, J., Li, Z., Li, J., Hulse, R. E., Santa-Cruz, A., Valinsky, W. C., . . Clapham, D. E. (2018a). Structure of the mammalian TRPM7, a magnesium channel required during embryonic development. Proceedings of the National Academy of Sciences of the United States of America, 115(35), E8201-E8210.

Duan, J., Li, Z., Li, J., Santa-Cruz, A., Sanchez-Martinez, S., Zhang, J., Clapham, D. E. (2018b). Structure of full-length human TRPM4. Proceedings of the National Academy of Sciences of the United States of America, 115(10), 2377-2382.

Duncan, L. M., Deeds, J., Cronin, F. E., Donovan, M., Sober, A. J., Kauffman, M., McCarthy, J. J. (2001). Melastatin expression and prognosis in cutaneous malignant melanoma. Journal of clinical oncology : official journal of the American Society of Clinical Oncology, 19(2), 568-576.

Duncan, L. M., Deeds, J., Hunter, J., Shao, J., Holmgren, L. M., Woolf, E. A., . . Shyjan, A. W. (1998). Down-regulation of the novel gene melastatin correlates with potential for melanoma metastasis. Cancer research, 58(7), 1515-1520.

Dutta Banik, D., Martin, L. E., Freichel, M., Torregrossa, A. M., Medler, K. F. (2018). TRPM4 and TRPM5 are both required for normal signaling in taste receptor cells. Proceedings of the National Academy of Sciences of the United States of America, 115(4), E772-E781.

Duvoisin, R. M., Haley, T. L., Ren, G., Strycharska-Orczyk, I., Bonaparte, J. P., Morgans, C. W. (2017). Autoantibodies in Melanoma-Associated Retinopathy Recognize an Epitope Conserved Between TRPM1 and TRPM3. Investigative ophthalmology \& visual science, 58(5), 2732-2738.

Earley, S., Waldron, B. J., Brayden, J. E. (2004). Critical role for transient receptor potential channel TRPM4 in myogenic constriction of cerebral arteries. Circ Res, 95(9), 922-929.

Ferioli, S., Zierler, S., Zaisserer, J., Schredelseker, J., Gudermann, T., Chubanov, V. (2017). TRPM6 and TRPM7 differentially contribute to the relief of heteromeric TRPM6/7 channels from inhibition by cytosolic $\mathrm{Mg}(2+)$ and Mg.ATP. Sci Rep, 7(1), 8806.

Garcia-Rodriguez, S., Rosal-Vela, A., Botta, D., Cumba Garcia, L. M., Zumaquero, E., Prados-Maniviesa, V., .. . Sancho, J. (2018). CD38 promotes pristane-induced chronic inflammation and increases susceptibility to experimental lupus by an apoptosis-driven and TRPM2-dependent mechanism. Sci Rep, 8(1), 3357.

Geng, Y., Zhao, Y., Schuster, L. C., Feng, B., Lynn, D. A., Austin, K. M., . . . Morrison, J. D. (2015). A Chemical Biology Study of Human Pluripotent Stem Cells Unveils HSPA8 as a Key Regulator of Pluripotency. Stem Cell Reports, 5(6), 1143-1154.

Gershkovitz, M., Caspi, Y., Fainsod-Levi, T., Katz, B., Michaeli, J., Khawaled, S., . . . Granot, Z. (2018). TRPM2 Mediates Neutrophil Killing of Disseminated Tumor Cells. Cancer research, 78(10), 26802690. 
Grand, T., Demion, M., Norez, C., Mettey, Y., Launay, P., Becq, F., . . . Guinamard, R. (2008). 9phenanthrol inhibits human TRPM4 but not TRPM5 cationic channels. British journal of pharmacology, 153(8), 1697-1705.

Guinamard, R., Hof, T., Del Negro, C. A. (2014). The TRPM4 channel inhibitor 9-phenanthrol. British journal of pharmacology, 171(7), 1600-1613.

Guo, J., She, J., Zeng, W., Chen, Q., Bai, X. C., Jiang, Y. (2017). Structures of the calcium-activated, nonselective cation channel TRPM4. Nature, 552(7684), 205-209.

Hall, D. P., Cost, N. G., Hegde, S., Kellner, E., Mikhaylova, O., Stratton, Y., . . . Czyzyk-Krzeska, M. F. (2014). TRPM3 and miR-204 establish a regulatory circuit that controls oncogenic autophagy in clear cell renal cell carcinoma. Cancer cell, 26(5), 738-753.

Han, S., Koo, H. H., Lan, Q., Lee, K. M., Park, A. K., Park, S. K., . . Kang, D. (2012). Common variation in genes related to immune response and risk of childhood leukemia. Hum Immunol, 73(3), 316319.

Hardie, R. C., Minke, B. (1992). The trp gene is essential for a light-activated Ca2+ channel in Drosophila photoreceptors. Neuron, 8(4), 643-651.

Hasselblatt, M., Mertsch, S., Koos, B., Riesmeier, B., Stegemann, H., Jeibmann, A., . . Paulus, W. (2009). TWIST-1 is overexpressed in neoplastic choroid plexus epithelial cells and promotes proliferation and invasion. Cancer research, 69(6), 2219-2223.

Held, K., Kichko, T., De Clercq, K., Klaassen, H., Van Bree, R., Vanherck, J. C., . . . Vriens, J. (2015). Activation of TRPM3 by a potent synthetic ligand reveals a role in peptide release. Proceedings of the National Academy of Sciences of the United States of America, 112(11), E1363-1372.

Hof, T., Liu, H., Salle, L., Schott, J. J., Ducreux, C., Millat, G., . . . Bouvagnet, P. (2017). TRPM4 nonselective cation channel variants in long QT syndrome. BMC Med Genet, 18(1), 31.

Holzmann, C., Kappel, S., Kilch, T., Jochum, M. M., Urban, S. K., Jung, V., . . Peinelt, C. (2015). Transient receptor potential melastatin 4 channel contributes to migration of androgen-insensitive prostate cancer cells. Oncotarget, 6(39), 41783-41793.

Huang, C., Qin, Y., Liu, H., Liang, N., Chen, Y., Ma, D., . . . Li, S. (2017a). Downregulation of a novel long noncoding RNA TRPM2-AS promotes apoptosis in non-small cell lung cancer. Tumour biology: the journal of the International Society for Oncodevelopmental Biology and Medicine, 39(2), 1010428317691191.

Huang, J., Furuya, H., Faouzi, M., Zhang, Z., Monteilh-Zoller, M., Kawabata, K. G., . . Fleig, A. (2017b). Inhibition of TRPM7 suppresses cell proliferation of colon adenocarcinoma in vitro and induces hypomagnesemia in vivo without affecting azoxymethane-induced early colon cancer in mice. Cell Commun Signal, 15(1), 30.

Huang, Y., Winkler, P. A., Sun, W., Lu, W., Du, J. (2018). Architecture of the TRPM2 channel and its activation mechanism by ADP-ribose and calcium. Nature, 562(7725), 145-149.

Huber, S. M. (2013). Oncochannels. Cell calcium, 53(4), 241-255.

Kale, V. P., Amin, S. G., Pandey, M. K. (2015). Targeting ion channels for cancer therapy by repurposing the approved drugs. Biochimica et biophysica acta, 1848(10 Pt B), 2747-2755.

Kaneko, S., Kawakami, S., Hara, Y., Wakamori, M., Itoh, E., Minami, T., . . Akaike, A. (2006). A critical role of TRPM2 in neuronal cell death by hydrogen peroxide. J Pharmacol Sci, 101(1), 66-76.

Katayama, K., Povalko, N., Yatsuga, S., Nishioka, J., Kakuma, T., Matsuishi, T., Koga, Y. (2015). New TRPM6 mutation and management of hypomagnesaemia with secondary hypocalcaemia. Brain Dev, 37(3), 292-298.

Kecskes, M., Jacobs, G., Kerselaers, S., Syam, N., Menigoz, A., Vangheluwe, P., . . Vennekens, R. (2015). The $\mathrm{Ca}(2+)$-activated cation channel TRPM4 is a negative regulator of angiotensin II-induced cardiac hypertrophy. Basic Res Cardiol, 110(4), 43. 
Kheradpezhouh, E., Barritt, G. J., Rychkov, G. Y. (2016). Curcumin inhibits activation of TRPM2 channels in rat hepatocytes. Redox Biol, 71-7.

Klose, C., Straub, I., Riehle, M., Ranta, F., Krautwurst, D., Ullrich, S., . . Harteneck, C. (2011). Fenamates as TRP channel blockers: mefenamic acid selectively blocks TRPM3. British journal of pharmacology, 162(8), 1757-1769.

Klumpp, D., Frank, S. C., Klumpp, L., Sezgin, E. C., Eckert, M., Edalat, L., . . Huber, S. M. (2017). TRPM8 is required for survival and radioresistance of glioblastoma cells. Oncotarget, 8(56), 95896-95913.

Klumpp, D., Misovic, M., Szteyn, K., Shumilina, E., Rudner, J., Huber, S. M. (2016). Targeting TRPM2 Channels Impairs Radiation-Induced Cell Cycle Arrest and Fosters Cell Death of T Cell Leukemia Cells in a Bcl-2-Dependent Manner. Oxid Med Cell Longev, 20168026702.

Koike, C., Obara, T., Uriu, Y., Numata, T., Sanuki, R., Miyata, K., . . . Furukawa, T. (2010). TRPM1 is a component of the retinal ON bipolar cell transduction channel in the mGluR6 cascade. Proceedings of the National Academy of Sciences of the United States of America, 107(1), 332337.

Kolisek, M., Beck, A., Fleig, A., Penner, R. (2005). Cyclic ADP-ribose and hydrogen peroxide synergize with ADP-ribose in the activation of TRPM2 channels. Molecular cell, 18(1), 61-69.

Koutsoukas, A., Lowe, R., Kalantarmotamedi, Y., Mussa, H. Y., Klaffke, W., Mitchell, J. B., . . Bender, A. (2013). In silico target predictions: defining a benchmarking data set and comparison of performance of the multiclass Naive Bayes and Parzen-Rosenblatt window. Journal of chemical information and modeling, 53(8), 1957-1966.

Krapivinsky, G., Krapivinsky, L., Renthal, N. E., Santa-Cruz, A., Manasian, Y., Clapham, D. E. (2017). Histone phosphorylation by TRPM6's cleaved kinase attenuates adjacent arginine methylation to regulate gene expression. Proceedings of the National Academy of Sciences of the United States of America, 114(34), E7092-E7100.

Krugel, U., Straub, I., Beckmann, H., Schaefer, M. (2017). Primidone inhibits TRPM3 and attenuates thermal nociception in vivo. Pain, 158(5), 856-867.

Kuipers, A. J., Middelbeek, J., Vrenken, K., Perez-Gonzalez, C., Poelmans, G., Klarenbeek, J., . . . van Leeuwen, F. N. (2018). TRPM7 controls mesenchymal features of breast cancer cells by tensional regulation of SOX4. Biochimica et biophysica acta, 1864(7), 2409-2419.

Kunnumakkara, A. B., Bordoloi, D., Harsha, C., Banik, K., Gupta, S. C., Aggarwal, B. B. (2017). Curcumin mediates anticancer effects by modulating multiple cell signaling pathways. Clin Sci (Lond), 131(15), 1781-1799.

Lashinger, E. S., Steiginga, M. S., Hieble, J. P., Leon, L. A., Gardner, S. D., Nagilla, R., . . Su, X. (2008). AMTB, a TRPM 8 channel blocker: evidence in rats for activity in overactive bladder and painful bladder syndrome. Am J Physiol Renal Physiol, 295(3), F803-810.

Launay, P., Cheng, H., Srivatsan, S., Penner, R., Fleig, A., Kinet, J. P. (2004). TRPM4 regulates calcium oscillations after T cell activation. Science, 306(5700), 1374-1377.

Launay, P., Fleig, A., Perraud, A. L., Scharenberg, A. M., Penner, R., Kinet, J. P. (2002). TRPM4 is a Ca2+activated nonselective cation channel mediating cell membrane depolarization. Cell, 109(3), 397-407.

Leanza, L., Manago, A., Zoratti, M., Gulbins, E., Szabo, I. (2016). Pharmacological targeting of ion channels for cancer therapy: In vivo evidences. Biochimica et biophysica acta, 1863(6 Pt B), 1385-1397.

Lee, Y., Yang, X., Huang, Y., Fan, H., Zhang, Q., Wu, Y., . . . Lussier, Y. A. (2010). Network modeling identifies molecular functions targeted by miR-204 to suppress head and neck tumor metastasis. PLoS Comput Biol, 6(4), e1000730.

Lelli, D., Pedone, C., Majeed, M., Sahebkar, A. (2017). Curcumin and Lung Cancer: the Role of microRNAs. Current pharmaceutical design, 23(23), 3440-3444. 
1023

1024

1025

1026

1027

1028

1029

1030

1031

1032

1033

1034

1035

1036

1037

1038

1039

1040

1041

1042

1043

Lemons, K., Fu, Z., Aoude, I., Ogura, T., Sun, J., Chang, J., . . . Lin, W. (2017). Lack of TRPM5-Expressing Microvillous Cells in Mouse Main Olfactory Epithelium Leads to Impaired Odor-Evoked Responses and Olfactory-Guided Behavior in a Challenging Chemical Environment. eNeuro, 4(3).

Leng, T. D., Li, M. H., Shen, J. F., Liu, M. L., Li, X. B., Sun, H. W., . . Xiong, Z. G. (2015). Suppression of TRPM7 inhibits proliferation, migration, and invasion of malignant human glioma cells. CNS Neurosci Ther, 21(3), 252-261.

Levy, C., Khaled, M., lliopoulos, D., Janas, M. M., Schubert, S., Pinner, S., . . Novina, C. D. (2010). Intronic miR-211 assumes the tumor suppressive function of its host gene in melanoma. Molecular cell, 40(5), 841-849.

Li, Q., Wang, X., Yang, Z., Wang, B., Li, S. (2009). Menthol induces cell death via the TRPM8 channel in the human bladder cancer cell line T24. Oncology, 77(6), 335-341.

Li, T., Pan, H., Li, R. (2016). The dual regulatory role of miR-204 in cancer. Tumour biology : the journal of the International Society for Oncodevelopmental Biology and Medicine, 37(9), 11667-11677.

Li, X., Wang, X., Xie, C., Zhu, J., Meng, Y., Chen, Y., . . Zhao, Y. (2018). Sonic hedgehog and Wnt/betacatenin pathways mediate curcumin inhibition of breast cancer stem cells. Anticancer Drugs, 29(3), 208-215.

Lin, R., Wang, Y., Chen, Q., Liu, Z., Xiao, S., Wang, B., Shi, B. (2018). TRPM2 promotes the proliferation and invasion of pancreatic ductal adenocarcinoma. Mol Med Rep, 17(6), 7537-7544.

Liu, B., Fan, L., Balakrishna, S., Sui, A., Morris, J. B., Jordt, S. E. (2013). TRPM8 is the principal mediator of menthol-induced analgesia of acute and inflammatory pain. Pain, 154(10), 2169-2177.

Liu, G., Wang, Y., Li, M. (2018a). Curcumin sensitized the antitumour effects of irradiation in promoting apoptosis of oesophageal squamous-cell carcinoma through NF-kappaB signalling pathway. $J$ Pharm Pharmacol, 70(10), 1340-1348.

Liu, J., Chen, Y., Shuai, S., Ding, D., Li, R., Luo, R. (2014). TRPM8 promotes aggressiveness of breast cancer cells by regulating EMT via activating AKT/GSK-3beta pathway. Tumour biology : the journal of the International Society for Oncodevelopmental Biology and Medicine, 35(9), 89698977.

Liu, T., Liao, Y., Tao, H., Zeng, J., Wang, G., Yang, Z., . . . Wang, X. (2018b). RNA interference-mediated depletion of TRPM8 enhances the efficacy of epirubicin chemotherapy in prostate cancer LNCaP and PC3 cells. Oncology letters, 15(4), 4129-4136.

Loh, K. P., Ng, G., Yu, C. Y., Fhu, C. K., Yu, D., Vennekens, R., . . . Liao, P. (2014). TRPM4 inhibition promotes angiogenesis after ischemic stroke. Pflugers Arch, 466(3), 563-576.

Loo, S. K., Ch'ng, E. S., Md Salleh, M. S., Banham, A. H., Pedersen, L. M., Moller, M. B., ... Wong, K. K. (2017). TRPM4 expression is associated with activated $B$ cell subtype and poor survival in diffuse large B cell lymphoma. Histopathology, 71(1), 98-111.

Luongo, F., Pietropaolo, G., Gautier, M., Dhennin-Duthille, I., Ouadid-Ahidouch, H., Wolf, F. I., Trapani, V. (2018). TRPM6 is Essential for Magnesium Uptake and Epithelial Cell Function in the Colon. Nutrients, 10(6).

Ma, L. Y., Xie, X. W., Ma, L., Pang, J. L., Xiong, X. M., Zheng, H. D., . . Wang, H. Y. (2017). Downregulated long non-coding RNA TRPM2-AS inhibits cisplatin resistance of non-small cell lung cancer cells via activation of p53- p66shc pathway. Eur Rev Med Pharmacol Sci, 21(11), 2626-2634.

Maeda, T., Suzuki, A., Koga, K., Miyamoto, C., Maehata, Y., Ozawa, S., . . . Kato, Y. (2017). TRPM5 mediates acidic extracellular $\mathrm{pH}$ signaling and TRPM5 inhibition reduces spontaneous metastasis in mouse B16-BL6 melanoma cells. Oncotarget, 8(45), 78312-78326.

Mathar, I., Vennekens, R., Meissner, M., Kees, F., Van der Mieren, G., Camacho Londono, J. E., . . . Freichel, M. (2010). Increased catecholamine secretion contributes to hypertension in TRPM4deficient mice. The Journal of clinical investigation, 120(9), 3267-3279. 
1044

1045

1046

1047

1048

1049

1050

1051

1052

1053

1054

1055

1056

1057

1058

1059

1060

1061

1062

1063

1064

1065

1066

1067

1068

1069

1070

1071

1072

1073

1074

1075

1076

1077

1078

1079

1080

1081

1082

1083

1084

1085

1086

1087

1088

1089

Meissner, T., Mark, A., Williams, C., Berdel, W. E., Wiebe, S., Kerkhoff, A., . . F Forster, M. (2017). Metastatic triple-negative breast cancer patient with TP53 tumor mutation experienced 11 months progression-free survival on bortezomib monotherapy without adverse events after ending standard treatments with grade 3 adverse events. Cold Spring Harb Mol Case Stud, 3(4).

Mervin, L. H., Afzal, A. M., Drakakis, G., Lewis, R., Engkvist, O., Bender, A. (2015). Target prediction utilising negative bioactivity data covering large chemical space. Journal of cheminformatics, 751.

Middelbeek, J., Kuipers, A. J., Henneman, L., Visser, D., Eidhof, I., van Horssen, R., . . Jalink, K. (2012). TRPM7 is required for breast tumor cell metastasis. Cancer research, 72(16), 4250-4261.

Mikhaylova, O., Stratton, Y., Hall, D., Kellner, E., Ehmer, B., Drew, A. F., . . Czyzyk-Krzeska, M. F. (2012). VHL-regulated MiR-204 suppresses tumor growth through inhibition of LC3B-mediated autophagy in renal clear cell carcinoma. Cancer cell, 21(4), 532-546.

Miraldi Utz, V., Pfeifer, W., Longmuir, S. Q., Olson, R. J., Wang, K., Drack, A. V. (2018). Presentation of TRPM1-Associated Congenital Stationary Night Blindness in Children. JAMA Ophthalmol, 136(4), 389-398.

Nadolni, W., Zierler, S. (2018). The Channel-Kinase TRPM7 as Novel Regulator of Immune System Homeostasis. Cells, 7(8).

Nair, A. V., Hocher, B., Verkaart, S., van Zeeland, F., Pfab, T., Slowinski, T., . . Hoenderop, J. G. (2012). Loss of insulin-induced activation of TRPM6 magnesium channels results in impaired glucose tolerance during pregnancy. Proceedings of the National Academy of Sciences of the United States of America, 109(28), 11324-11329.

Nakano, Y., Le, M. H., Abduweli, D., Ho, S. P., Ryazanova, L. V., Hu, Z., . . Zhang, Y. (2016). A Critical Role of TRPM7 As an Ion Channel Protein in Mediating the Mineralization of the Craniofacial Hard Tissues. Front Physiol, 7258.

Narayan, G., Bourdon, V., Chaganti, S., Arias-Pulido, H., Nandula, S. V., Rao, P. H., . . Murty, V. V. (2007). Gene dosage alterations revealed by cDNA microarray analysis in cervical cancer: identification of candidate amplified and overexpressed genes. Genes, chromosomes \& cancer, 46(4), 373-384.

Naylor, J., Li, J., Milligan, C. J., Zeng, F., Sukumar, P., Hou, B., . . Beech, D. J. (2010). Pregnenolone sulphate- and cholesterol-regulated TRPM3 channels coupled to vascular smooth muscle secretion and contraction. Circ Res, 106(9), 1507-1515.

Ogata, K., Tsumuraya, T., Oka, K., Shin, M., Okamoto, F., Kajiya, H., . . O Okabe, K. (2017). The crucial role of the TRPM7 kinase domain in the early stage of amelogenesis. Sci Rep, 7(1), 18099.

Okamoto, Y., Ohkubo, T., Ikebe, T., Yamazaki, J. (2012). Blockade of TRPM8 activity reduces the invasion potential of oral squamous carcinoma cell lines. Int J Oncol, 4O(5), 1431-1440.

Orfanelli, U., Jachetti, E., Chiacchiera, F., Grioni, M., Brambilla, P., Briganti, A., . . L Lavorgna, G. (2015). Antisense transcription at the TRPM2 locus as a novel prognostic marker and therapeutic target in prostate cancer. Oncogene, 34(16), 2094-2102.

Orfanelli, U., Wenke, A. K., Doglioni, C., Russo, V., Bosserhoff, A. K., Lavorgna, G. (2008). Identification of novel sense and antisense transcription at the TRPM2 locus in cancer. Cell Res, 18(11), 11281140.

Ozhathil, L. C., Delalande, C., Bianchi, B., Nemeth, G., Kappel, S., Thomet, U., . . . Abriel, H. (2018). Identification of potent and selective small molecule inhibitors of the cation channel TRPM4. British journal of pharmacology, 175(12), 2504-2519.

Palmer, R. K., Atwal, K., Bakaj, I., Carlucci-Derbyshire, S., Buber, M. T., Cerne, R., . . Bryant, R. (2010). Triphenylphosphine oxide is a potent and selective inhibitor of the transient receptor potential melastatin-5 ion channel. Assay Drug Dev Technol, 8(6), 703-713. 
Pan, R. Y., Liu, P., Zhou, H. T., Sun, W. X., Song, J., Shu, J., . . . Jia, E. Z. (2017). Circular RNAs promote TRPM3 expression by inhibiting hsa-miR-130a-3p in coronary artery disease patients. Oncotarget, 8(36), 60280-60290.

Pardo, L. A., del Camino, D., Sanchez, A., Alves, F., Bruggemann, A., Beckh, S., Stuhmer, W. (1999). Oncogenic potential of EAG K(+) channels. EMBO J, 18(20), 5540-5547.

Park, Y. R., Chun, J. N., So, I., Kim, H. J., Baek, S., Jeon, J. H., Shin, S. Y. (2016). Data-driven Analysis of TRP Channels in Cancer: Linking Variation in Gene Expression to Clinical Significance. Cancer Genomics Proteomics, 13(1), 83-90.

Peng, M., Wang, Z., Yang, Z., Tao, L., Liu, Q., Yi, L. U., Wang, X. (2015). Overexpression of short TRPM8 variant alpha promotes cell migration and invasion, and decreases starvation-induced apoptosis in prostate cancer LNCaP cells. Oncology letters, 10(3), 1378-1384.

Persad, P. J., Heid, I. M., Weeks, D. E., Baird, P. N., de Jong, E. K., Haines, J. L., . . . International AgeRelated Macular Degeneration Genomics, C. (2017). Joint Analysis of Nuclear and Mitochondrial Variants in Age-Related Macular Degeneration Identifies Novel Loci TRPM1 and ABHD2/RLBP1. Investigative ophthalmology \& visual science, 58(10), 4027-4038.

Philippaert, K., Pironet, A., Mesuere, M., Sones, W., Vermeiren, L., Kerselaers, S., . . Vennekens, R. (2017). Steviol glycosides enhance pancreatic beta-cell function and taste sensation by potentiation of TRPM5 channel activity. Nat Commun, 814733.

Prawitt, D., Enklaar, T., Klemm, G., Gartner, B., Spangenberg, C., Winterpacht, A., . . Zabel, B. (2000). Identification and characterization of MTR1, a novel gene with homology to melastatin (MLSN1) and the trp gene family located in the BWS-WT2 critical region on chromosome 11p15.5 and showing allele-specific expression. Human molecular genetics, 9(2), 203-216.

Prevarskaya, N., Skryma, R., Shuba, Y. (2018). Ion Channels in Cancer: Are Cancer Hallmarks Oncochannelopathies? Physiol Rev, 98(2), 559-621.

Quallo, T., Vastani, N., Horridge, E., Gentry, C., Parra, A., Moss, S., . . Bevan, S. (2015). TRPM8 is a neuronal osmosensor that regulates eye blinking in mice. Nat Commun, 67150.

Rah, S. Y., Kwak, J. Y., Chung, Y. J., Kim, U. H. (2015). ADP-ribose/TRPM2-mediated Ca2+ signaling is essential for cytolytic degranulation and antitumor activity of natural killer cells. Sci Rep, 59482.

Ryazanova, L. V., Rondon, L. J., Zierler, S., Hu, Z., Galli, J., Yamaguchi, T. P., . . Ryazanov, A. G. (2010). TRPM7 is essential for $\mathrm{Mg}(2+)$ homeostasis in mammals. Nat Commun, 1109.

Rybarczyk, P., Vanlaeys, A., Brassart, B., Dhennin-Duthille, I., Chatelain, D., Sevestre, H., . . Gautier, M. (2017). The Transient Receptor Potential Melastatin 7 Channel Regulates Pancreatic Cancer Cell Invasion through the Hsp90alpha/uPA/MMP2 pathway. Neoplasia, 19(4), 288-300.

Sacconi, A., Biagioni, F., Canu, V., Mori, F., Di Benedetto, A., Lorenzon, L., . . Blandino, G. (2012). miR204 targets Bcl-2 expression and enhances responsiveness of gastric cancer. Cell Death Dis, $3 \mathrm{e} 423$.

Sagredo, A. I., Sagredo, E. A., Cappelli, C., Baez, P., Andaur, R. E., Blanco, C., . . A Armisen, R. (2018). TRPM4 regulates Akt/GSK3-beta activity and enhances beta-catenin signaling and cell proliferation in prostate cancer cells. Mol Oncol, 12(2), 151-165.

Schinke, E. N., Bii, V., Nalla, A., Rae, D. T., Tedrick, L., Meadows, G. G., Trobridge, G. D. (2014). A novel approach to identify driver genes involved in androgen-independent prostate cancer. Molecular cancer, 13120.

Schmitz, C., Perraud, A. L. (2005). The TRPM cation channels in the immune context. Current pharmaceutical design, 11(21), 2765-2778.

Song, C., Bae, Y., Jun, J., Lee, H., Kim, N. D., Lee, K. B., . . Sim, T. (2017). Identification of TG100-115 as a new and potent TRPM7 kinase inhibitor, which suppresses breast cancer cell migration and invasion. Biochim Biophys Acta Gen Subj, 1861(4), 947-957. 
Song, K., Wang, H., Kamm, G. B., Pohle, J., Reis, F. C., Heppenstall, P., . . Siemens, J. (2016). The TRPM2 channel is a hypothalamic heat sensor that limits fever and can drive hypothermia. Science, 353(6306), 1393-1398.

Stephens, P. J., Tarpey, P. S., Davies, H., Van Loo, P., Greenman, C., Wedge, D. C., . . Stratton, M. R. (2012). The landscape of cancer genes and mutational processes in breast cancer. Nature, 486(7403), 400-404.

Straub, I., Krugel, U., Mohr, F., Teichert, J., Rizun, O., Konrad, M., . . Schaefer, M. (2013). Flavanones that selectively inhibit TRPM3 attenuate thermal nociception in vivo. Mol Pharmacol, 84(5), 736750.

Suguro, M., Tagawa, H., Kagami, Y., Okamoto, M., Ohshima, K., Shiku, H., . . Seto, M. (2006). Expression profiling analysis of the CD5+ diffuse large B-cell lymphoma subgroup: development of a CD5 signature. Cancer science, 97(9), 868-874.

Sumoza-Toledo, A., Penner, R. (2011). TRPM2: a multifunctional ion channel for calcium signalling. J Physiol, 589(Pt 7), 1515-1525.

Sun, Y., Schaar, A., Sukumaran, P., Dhasarathy, A., Singh, B. B. (2018a). TGFbeta-induced epithelial-tomesenchymal transition in prostate cancer cells is mediated via TRPM7 expression. Molecular carcinogenesis, 57(6), 752-761.

Sun, Y., Sukumaran, P., Selvaraj, S., Cilz, N. I., Schaar, A., Lei, S., Singh, B. B. (2018b). TRPM2 Promotes Neurotoxin MPP(+)/MPTP-Induced Cell Death. Mol Neurobiol, 55(1), 409-420.

Syed Mortadza, S. A., Wang, L., Li, D., Jiang, L. H. (2015). TRPM2 Channel-Mediated ROS-Sensitive Ca(2+) Signaling Mechanisms in Immune Cells. Front Immunol, 6407.

Talavera, K., Yasumatsu, K., Voets, T., Droogmans, G., Shigemura, N., Ninomiya, Y., . . Nilius, B. (2005). Heat activation of TRPM5 underlies thermal sensitivity of sweet taste. Nature, 438(7070), 10221025.

Tan, C. H., McNaughton, P. A. (2016). The TRPM2 ion channel is required for sensitivity to warmth. Nature, 536(7617), 460-463.

Tian, B., Zhao, Y., Liang, T., Ye, X., Li, Z., Yan, D., . . . Li, Y. (2017). Curcumin inhibits urothelial tumor development by suppressing IGF2 and IGF2-mediated PI3K/AKT/mTOR signaling pathway. J Drug Target, 25(7), 626-636.

Togashi, K., Inada, H., Tominaga, M. (2008). Inhibition of the transient receptor potential cation channel TRPM2 by 2-aminoethoxydiphenyl borate (2-APB). British journal of pharmacology, 153(6), 1324-1330.

Turlova, E., Bae, C. Y. J., Deurloo, M., Chen, W., Barszczyk, A., Horgen, F. D., . . Sun, H. S. (2016). TRPM7 Regulates Axonal Outgrowth and Maturation of Primary Hippocampal Neurons. Mol Neurobiol, 53(1), 595-610.

van Genderen, M. M., Bijveld, M. M., Claassen, Y. B., Florijn, R. J., Pearring, J. N., Meire, F. M., . . . Kamermans, M. (2009). Mutations in TRPM1 are a common cause of complete congenital stationary night blindness. American journal of human genetics, 85(5), 730-736.

Vennekens, R., Mesuere, M., Philippaert, K. (2018). TRPM5 in the battle against diabetes and obesity. Acta Physiol (Oxf), 222(2).

Voets, T., Nilius, B., Hoefs, S., van der Kemp, A. W., Droogmans, G., Bindels, R. J., Hoenderop, J. G. (2004). TRPM6 forms the Mg2+ influx channel involved in intestinal and renal Mg2+ absorption. The Journal of biological chemistry, 279(1), 19-25.

Vriens, J., Nilius, B., Vennekens, R. (2008). Herbal compounds and toxins modulating TRP channels. Curr Neuropharmacol, 6(1), 79-96.

Vriens, J., Owsianik, G., Hofmann, T., Philipp, S. E., Stab, J., Chen, X., . . Voets, T. (2011). TRPM3 is a nociceptor channel involved in the detection of noxious heat. Neuron, 70(3), 482-494. 
Wagner, T. F., Loch, S., Lambert, S., Straub, I., Mannebach, S., Mathar, I., . . O Oberwinkler, J. (2008). Transient receptor potential M3 channels are ionotropic steroid receptors in pancreatic beta cells. Nat Cell Biol, 10(12), 1421-1430.

Walder, R. Y., Landau, D., Meyer, P., Shalev, H., Tsolia, M., Borochowitz, Z., . . Sheffield, V. C. (2002). Mutation of TRPM6 causes familial hypomagnesemia with secondary hypocalcemia. Nature genetics, 31(2), 171-174.

Wang, L., Fu, T. M., Zhou, Y., Xia, S., Greka, A., Wu, H. (2018a). Structures and gating mechanism of human TRPM2. Science.

Wang, Q., Huang, L., Yue, J. (2017). Oxidative stress activates the TRPM2-Ca2+-CaMKII-ROS signaling loop to induce cell death in cancer cells. Biochimica et biophysica acta, 1864(6), 957-967.

Wang, W. H., Chen, J., Zhang, B. R., Lu, S. J., Wang, F., Peng, L., . . Sun, Y. Z. (2018b). Curcumin inhibits proliferation and enhances apoptosis in A549 cells by downregulating IncRNA UCA1. Pharmazie, 73(7), 402-407.

Weber, K. S., Hildner, K., Murphy, K. M., Allen, P. M. (2010). Trpm4 differentially regulates Th1 and Th2 function by altering calcium signaling and NFAT localization. J Immunol, 185(5), 2836-2846.

Winkler, P. A., Huang, Y., Sun, W., Du, J., Lu, W. (2017). Electron cryo-microscopy structure of a human TRPM4 channel. Nature, 552(7684), 200-204.

Wong, R., Turlova, E., Feng, Z. P., Rutka, J. T., Sun, H. S. (2017). Activation of TRPM7 by naltriben enhances migration and invasion of glioblastoma cells. Oncotarget, 8(7), 11239-11248.

Xiong, W. H., Brown, R. L., Reed, B., Burke, N. S., Duvoisin, R. M., Morgans, C. W. (2015). Voriconazole, an antifungal triazol that causes visual side effects, is an inhibitor of TRPM1 and TRPM3 channels. Investigative ophthalmology \& visual science, 56(2), 1367-1373.

Xu, Y., Orlandi, C., Cao, Y., Yang, S., Choi, C. I., Pagadala, V., . . . Vardi, N. (2016). The TRPM1 channel in ON-bipolar cells is gated by both the alpha and the betagamma subunits of the G-protein Go. Sci Rep, 620940.

Yapa, K., Deuis, J., Peters, A. A., Kenny, P. A., Roberts-Thomson, S. J., Vetter, I., Monteith, G. R. (2018). Assessment of the TRPM8 inhibitor AMTB in breast cancer cells and its identification as an inhibitor of voltage gated sodium channels. Life Sci, 198128-135.

Yee, N. S. (2015). Roles of TRPM8 Ion Channels in Cancer: Proliferation, Survival, and Invasion. Cancers (Basel), 7(4), 2134-2146.

Yee, N. S. (2017). Role of TRPM7 in Cancer: Potential as Molecular Biomarker and Therapeutic Target. Pharmaceuticals (Basel), 10(2).

Yee, N. S., Brown, R. D., Lee, M. S., Zhou, W., Jensen, C., Gerke, H., Yee, R. K. (2012). TRPM8 ion channel is aberrantly expressed and required for preventing replicative senescence in pancreatic adenocarcinoma: potential role of TRPM8 as a biomarker and target. Cancer Biol Ther, 13(8), 592-599.

Yin, Y., Wu, M., Zubcevic, L., Borschel, W. F., Lander, G. C., Lee, S. Y. (2018). Structure of the cold- and menthol-sensing ion channel TRPM8. Science, 359(6372), 237-241.

Ying, Z., Li, Y., Wu, J., Zhu, X., Yang, Y., Tian, H., . . Li, M. (2013). Loss of miR-204 expression enhances glioma migration and stem cell-like phenotype. Cancer research, 73(2), 990-999.

Yoshida, K., Toden, S., Ravindranathan, P., Han, H., Goel, A. (2017). Curcumin sensitizes pancreatic cancer cells to gemcitabine by attenuating PRC2 subunit EZH2, and the IncRNA PVT1 expression. Carcinogenesis, 38(10), 1036-1046.

Zeng, X., Feng, Q., Zhao, F., Sun, C., Zhou, T., Yang, J., Zhan, X. (2018). Puerarin inhibits TRPM3/miR-204 to promote MC3T3-E1 cells proliferation, differentiation and mineralization. Phytother Res, 32(6), 996-1003. 
Zeng, X., Sikka, S. C., Huang, L., Sun, C., Xu, C., Jia, D., . . Li, M. (2010). Novel role for the transient receptor potential channel TRPM2 in prostate cancer cell proliferation. Prostate Cancer Prostatic Dis, 13(2), 195-201.

Zhang, Y., Cai, Q., Shu, X. O., Gao, Y. T., Li, C., Zheng, W., Long, J. (2015). Whole-Exome Sequencing Identifies Novel Somatic Mutations in Chinese Breast Cancer Patients. J Mol Genet Med, 9(4).

Zhang, Z., Faouzi, M., Huang, J., Geerts, D., Yu, H., Fleig, A., Penner, R. (2014a). N-Myc-induced upregulation of TRPM6/TRPM7 channels promotes neuroblastoma cell proliferation. Oncotarget, 5(17), 7625-7634.

Zhang, Z., Toth, B., Szollosi, A., Chen, J., Csanady, L. (2018). Structure of a TRPM2 channel in complex with $\mathrm{Ca}(2+)$ explains unique gating regulation. Elife, 7 .

Zhang, Z., Yu, H., Huang, J., Faouzi, M., Schmitz, C., Penner, R., Fleig, A. (2014b). The TRPM6 kinase domain determines the Mg.ATP sensitivity of TRPM7/M6 heteromeric ion channels. The Journal of biological chemistry, 289(8), 5217-5227.

Zhao, L. Y., Xu, W. L., Xu, Z. Q., Qi, C., Li, Y., Cheng, J., . . Ye, J. H. (2016). The overexpressed functional transient receptor potential channel TRPM2 in oral squamous cell carcinoma. Sci Rep, 638471.

Zhao, W., Xu, H. (2016). High expression of TRPM8 predicts poor prognosis in patients with osteosarcoma. Oncology letters, 12(2), 1373-1379.

Zhiqi, S., Soltani, M. H., Bhat, K. M., Sangha, N., Fang, D., Hunter, J. J., Setaluri, V. (2004). Human melastatin 1 (TRPM1) is regulated by MITF and produces multiple polypeptide isoforms in melanocytes and melanoma. Melanoma Res, 14(6), 509-516.

Zhou, L., Li, T., Xing, Y. Q., Li, Y., Wu, Q. S., Zhang, M. J. (2016). Novel TRPM1 mutations in two Chinese families with early-onset high myopia, with or without complete congenital stationary night blindness. Int J Ophthalmol, 9(10), 1396-1402.

Zierler, S., Sumoza-Toledo, A., Suzuki, S., Duill, F. O., Ryazanova, L. V., Penner, R., . . Fleig, A. (2016). TRPM7 kinase activity regulates murine mast cell degranulation. J Physiol, 594(11), 2957-2970.

Zierler, S., Yao, G., Zhang, Z., Kuo, W. C., Porzgen, P., Penner, R., ... Fleig, A. (2011). Waixenicin A inhibits cell proliferation through magnesium-dependent block of transient receptor potential melastatin 7 (TRPM7) channels. The Journal of biological chemistry, 286(45), 39328-39335. 
1272 Figure 1: Normal physiological functions of activated TRPM ion channels

1273 In TRPM1, glutamate released from rods binds to the metabotropic glutamate receptor 6 1274 (mGluR6) of ON-bipolar cells of the retina, subsequently activates heterotrimeric G-protein 1275 subunits ( $G_{0} \alpha$ and $G \beta Y$ ) and causes the closure of TRPM1 channel which allows the visual 1276 signal to be transmitted in low-light condition. Closure of the channel prevents the influx of $\mathrm{Na}^{+}$ 1277 and $\mathrm{Ca}^{2+}$ ions. In TRPM2, the vascular endothelial growth factor (VEGF)-induced angiogenesis 1278 activates reactive oxygen species (ROS) to release adenosine diphosphate (ADP)-ribose. 1279 TRPM2 activated by ADP-ribose allows the influx of $\mathrm{Ca}^{2+}$ ion. This channel has sensitivity 1280 towards heat (body temperature). TRPM3 is activated by steroid pregnenolone sulphate (PS), 1281 allowing influx of $\mathrm{Ca}^{2+}$ ion. TRPM4 is activated by increased concentration of intracellular $\mathrm{Ca}^{2+}$ $1282\left[\mathrm{Ca}^{2+}\right]$, which allows the influx of monovalent ions only such as $\mathrm{K}^{+}$and $\mathrm{Na}^{+}$ion. TRPM5, another 1283 monovalent cation-selective channel activated by increased $\left[\mathrm{Ca}^{2+}\right]_{\mathrm{I}}$, allows the influx of $\mathrm{Na}^{+}, \mathrm{K}^{+}$ 1284 and $\mathrm{Cs}^{+}$. TRPM6 is a channel kinase with a TRP channel permeable to $\mathrm{Mg}^{2+}$ and $\mathrm{Ca}^{2+}$. The 1285 channel is activated by depletion of $\mathrm{Mg}^{2+}$ or autophosphorylation of its Ser/Thr-rich kinase 1286 domain. TRPM7 is another channel kinase that allows the influx $\mathrm{Mg}^{2+}$ or $\mathrm{Ca}^{2+}$. TRPM8 is 1287 sensitive to increased levels of intracellular $\mathrm{pH}$, and it is permeable to $\mathrm{Ca}^{2+}, \mathrm{Na}^{+}$and $\mathrm{K}^{+}$. TRPM8 1288 is activated by cold temperatures and chemical cooling compounds such as menthol and 1289 eucalyptol.

Figure 2: Oncogenic functions and signaling pathways mediated by TRPM2, TRPM3 and

1293 TRPM2: LC3A/B II, ATGs and BNIP3 are autophagy- and mitophagy-associated proteins 1294 (Almasi et al., 2018). The IncRNA TRPM2-AS exerting its effects in prostate cancer (Orfanelli et 1295 al., 2015) and NSCLC (Huang et al., 2017a; Ma et al., 2017) are depicted here independent of 1296 TRPM2 channel activity. TRPM3: miR-204 directly or indirectly (through CAV1) inhibits TRPM3. $1297 \mathrm{Zn}^{2+}$ fluxes via TRPM3 inhibit miR-214 which directly suppress transcription of LC3A/B (required 1298 for autophagy) by binding their 3' UTRs. Autophagy involves degradation of protein aggregates, 1299 mitochondria and cytoplasmic components to generate nutrients for cCRCC growth (Hall et al., 1300 2014). TRPM4: TRPM4 was a negative feedback regulator of SOCE in the prostate cancer cells 1301 DU145 through large influx of $\mathrm{Na}^{+}$that reduced the driving force for $\mathrm{Ca}^{2+}$ influx. The reduced 1302 migration of TRPM4-depleted DU145 cells by siRNA might be due to negative regulation by 
$1303 \mathrm{Ca}^{2+}$-dependent mechanism such as SOCE (Holzmann et al., 2015). This remains to be 1304 validated by future independent assessments as another study (Sagredo et al., 2018) showed a 1305 decrease in SOCE in TRPM4-depleted PC3 cells by shRNA, hence the symbol '?' was 1306 presented in between the inhibition and activation arrows involving $\mathrm{Na}^{+}$and TRPM4, 1307 respectively, directed towards SOCE. GCC: Gastric cancer cell; PCa: Prostate cancer.

Figure 3: Oncogenic functions and signaling pathways mediated by TRPM5, TRPM7 and

1311 TRPM5: Activities of TRPM5 increased acidic extracellular pH $\left(\mathrm{pH}_{e}\right)$ signal. TPPO 1312 (triphenylphosphine oxide, inhibitor of TRPM5) reduced NF-kB activity and expression of EMT1313 associated genes (Mmp9, Vim, Cdh2) (Palmer et al., 2010). TRPM7: Induction of Hsp90a 1314 secretion promoted stabilization of pro-MMP2 and UPA that induced production of MMP2, 1315 triggering increased degradation of the ECM and invasion of PDAC cells (Rybarczyk et al., 1316 2017); Transforming growth factor $\beta$ (TGF $\beta$ )-induced cell migration likely required $\mathrm{Mg}^{2+}$ influx by 1317 TRPM7 that induced expression of proteins involved in reduced cell-cell adhesion (E-cadherin) 1318 but increased mesenchymal phenotype such as vimentin (and N-cadherin) that promoted EMT 1319 and invasion of prostate cancer cells (Sun et al., 2018a); In breast cancer cells, activities of 1320 TRPM7 decreased cytoskeletal tension that subsequently increased expression of the EMT 1321 transcription factor SOX4 that promoted EMT through reduction of cell adhesion molecules such 1322 as E-cadherin (Kuipers et al., 2018). TRPM8: $\mathrm{Ca}^{2+}$ influx through TRPM8 upregulated activation 1323 of CaMKII, cdc25c and cdc2 that inhibited G2/M arrest. Increased BK $\mathrm{K}^{+}$channel activity 1324 contributed to increased migration and chemotaxis (Klumpp et al., 2017); Knockdown of full1325 length TRPM8 and SM8 isoforms induced ER stress and mitochondrial oxidative stress that 1326 increased PERK [protein kinase RNA (PKR)-like ER kinase] pathway that contributed to 1327 induction of p21 (restricts cell cycle progression) and apoptosis of prostate cancer cells (Bidaux 1328 et al., 2016). Breast ca: Breast cancer; PCa: Prostate cancer.

1330 Graphical abstract: Here, we summarized and discussed the oncogenic properties of TRPM 1331 ion channels in various types of malignancies, and their potential as therapeutic targets. The 1332 normal physiological functions of each TRPM were first introduced before their relevance with 1333 cancers were described and discussed. 